\title{
A Mesoscale Analysis Method for Surface Potential Temperature in Mountainous and Coastal Terrain
}

\author{
XingXiu Deng And Roland Stull \\ University of British Columbia, Vancouver, British Columbia, Canada
}

(Manuscript received 20 December 2003, in final form 19 July 2004)

\begin{abstract}
A technique is developed to anisotropically spread surface observations in steep valleys. The goal is to create an improved objective analysis for the lowest, terrain-following numerical weather prediction (NWP) model level in mountainous terrain.

The method is a mother-daughter (MD) approach, where the amount of information transferred from one grid point (the mother) to all neighboring grid points (the daughters) depends on elevation differences. The daughters become mothers and further share information with their neighboring grid points. This iterative method allows information to follow valleys around ridges, while reducing spread over the ridge top. The method is further refined to account for land-sea anisotropy.

This approach is tested in the objective analyses of surface potential temperatures over the steep mountainous and coastal terrain of southwestern British Columbia, Canada. Analysis results are compared with other existing schemes using the Advanced Regional Prediction System Data Assimilation System (ADAS). It is found that the MD approach outperforms the other schemes over mountainous and coastal terrain.
\end{abstract}

\section{Introduction}

Objective analysis transforms information from randomly spaced observing sites into data at regularly spaced grid points (Krishnamurti and Bounoua 1996). It is often done by optimally combining observations and a short-range NWP forecast, called a first guess (background). Analysis schemes, such as optimum interpolation (OI) (Daley 1991), successive corrections (Bratseth 1986), and 3D variational analysis (Laroche et al. 1999), require the specification of a covariance function to model the spatial correlations of background errors. The background error covariance, used to define the optimum weights for data spreading, is often assumed to be isotropic.

Isotropy, however, is a questionable assumption for mesoscale analyses or for analyses in mountainous/ coastal regions. Therefore, flow-dependent or anisotropic covariance models are receiving more attention, such as by introducing isentropic (Benjamin et al. 1991) or semigeostrophic (Desroziers 1997) coordinate transformations in analysis increments. Flow-dependent background error covariance can also be estimated explicitly by Kalman filtering (KF), implicitly by 4D

Corresponding author address: Xingxiu Deng, Dept. of Earth and Ocean Sciences, University of British Columbia, 6339 Stores Rd., Vancouver, BC V6T 1Z4, Canada.

E-mail: xdeng@eos.ubc.ca variational data assimilation (4DVAR) methods, or approximated in the ensemble Kalman filter (EnKF) (Gauthier et al. 1993; Bouttier 1993; Thépaut et al. 1996; Houtekamer and Mitchell 1998, 2001). But KF, 4DVAR, and EnKF are computationally time consuming. Lanzinger and Steinacker (1990) incorporated anisotropic correlation structures due to orography, to resolve sharp gradients across major mountain ridges (Alps, Pyrrenees). Miller and Benjamin (1992) used elevation differences in correlation functions to account for terrain effects.

Present computing power allows fine-grid NWP models to resolve small mesoscale flows within individual valleys. Such resolution is important, because in steep mountainous terrain the valleys contain most of the population centers, industries, and transportation routes. To this end, the Mesoscale Compressible Community (MC2) model (Benoit et al. 1997; Laprise et al. 1997) has been running daily for several years at the University of British Columbia (UBC). MC2 is a fully compressible model using semi-implicit semiLagrangian techniques. Currently, the daily forecasts at UBC start with $108-\mathrm{km}$ grid spacing, initialized from the Eta analysis, and then one-way nest down to 36, 12, 4 , and $2 \mathrm{~km}$. The two finest grids can resolve different weather in separate neighboring valleys. Accurate fineresolution forecasts depend on accurate and representative initial fields from which to start. This study focuses on the surface data analysis at the lowest, terrainfollowing MC2 model level. 
The Advanced Regional Prediction System (ARPS) (Xue et al. 2000) Data Assimilation System (ADAS) (CAPS 1995; Brewster 1996) in ARPS5.0.0 Beta8 is used as an analysis tool. The ADAS employs the successive-correction method of Bratseth (1986), requiring less computational time than other advanced methods (i.e., KF and 4DVAR). This allows near-real-time, high-resolution analysis over most of British Columbia (BC), Canada, using moderately powerful computers.

In the mountainous terrain of western North America, many surface observation sites are located in deep valleys. Both the background error covariance and representativeness of surface observations are affected by heterogeneous terrain. BC has a variety of landscapes from seashores, straits, and fjords to mountains and valleys. Some valleys are narrow and long with kinks and twists. The need for weather data at many sites in a valley is often not matched by the availability of weather stations. Typically, villages are strung along valley floors, with ski resorts higher up the slopes and reservoirs in tributary valleys. Observations from a surface weather station at one village in the valley is often not representative of conditions up- or downvalley nor is it representative of conditions on nearby mountain slopes. Similarly, weather observations at ridge top would not be representative of surface weather in the adjacent valley.

This typical scenario stimulates the following question. At locations (in that one valley) distant from the observation station, which of the following better represents the initial air state: 1) the first guess (from a previous high-resolution forecast) or 2) the observations from the distant station? An experiment to address this question would be to densely instrument the valley, and to determine the correlations. However, it is likely that the conclusions would apply only to that one valley. It might also be risky to apply results from other densely instrumented valleys (e.g., the Mesoscale Alpine Project) to the valleys in $\mathrm{BC}$.

Within the constraints of the present numerical experiments, we hypothesize that in a serpentine valley, the first guess (from a fine-resolution NWP model) is better than a distant observation from the same valley, in the absence of dense intravalley observations. This hypothesis herein is referred to as the intravalley decorrelation assumption. An extension of this hypothesis treats two valleys separated by a high ridge and herein is referred to as the intervalley decorrelation assumption. If there is an observation in only one valley, then the first guess in the noninstrumented valley represents the air state better than the observation from the other valley.

We implement the intravalley and intervalley decorrelation hypotheses within the ADAS Bratseth scheme for data assimilation in complex terrain. The intravalley assumption uses a Gaussian drop-off with distance from the observation, where distance is measured along the circuitous path of the valley. The intervalley assumption uses an anisotropic term that reduces data spreading into terrain of differing elevation.

A mother-daughter (MD) approach is proposed here to calculate the anisotropic term and circuitous travel distance (CTD). The anisotropic effect is introduced via a "sharing factor," namely, the fraction of information shared between an observation and analysis grid point (GP). Near coastlines, land-sea anisotropy is also included.

Section 2 describes the ADAS, and modifications for this study. Section 3 reviews basic concepts of atmospheric boundary layers (BLs) in mountainous terrain. The MD approach is presented in section 4. Numerical experiments are given in section 5 . In section 6 , with case examples we demonstrate characteristics and advantages of the MD approach over two other schemes. Computational costs are also examined. Summary and discussions are in section 7 , and a sensitivity analysis is in the appendix.

\section{The analysis tool}

\section{a. General description}

The ADAS was developed by the Center for Analysis and Prediction of Storms (CAPS, University of Oklahoma). It is a 3D mesoscale analysis system that ingests and analyzes meteorological data from different observational sources. The ADAS is efficient, easily implemented and attractive for high-resolution analysis on model levels.

The ADAS combines observations with a first guess using the Bratseth (1986) scheme, which converges to OI. Like OI, the Bratseth scheme accounts for the relative error between the observations and the first guess. Different from OI, this scheme iterates without the inversion of large matrices, and requires less computer resources.

The ADAS has gained wide usage in research and operational forecasting. Research applications for a strong cold-front passage (Ciliberti et al. 1999) and sensitivity experiments (Ciliberti et al. 2000) showed that realistic local and mesoscale structures can be analyzed with the aid of local data. Operational applications included short-range weather forecasts over east-central Florida (Case et al. 2002), weather support for the 2002 Winter Olympics (Horel et al. 2002), and near-real-time applications to complex terrain in the western United States (Lazarus et al. 2002). Lazarus et al. (2002) introduced into the ADAS a terrain factor for surface data. ${ }^{1}$ The terrain factor affects only the analysis in the free atmosphere.

\footnotetext{
${ }^{1}$ This was expanded for 3D data (surface and sounding data) by Keith Brewster (CAPS 2004, personal communication) in a newer version (ARPS5.1.0).
} 


\section{b. Modifications}

\section{1) ADAS VERSUS MC2 GRIDS}

For better analysis quality, analyses are performed directly on the MC2 grid using MC2 output as firstguess fields.

\section{2) Quality control}

For surface observations, quality control includes climatological checks, temporal checks, horizontal consistency checks [Barnes (1964) technique], and observation-to-background difference checks.

For case studies with virtual observations (section 6a), no quality control is needed. For case studies with real observations (section 6b), the horizontal consistency checks and observation-to-background difference checks are turned off for the following reasons. The Barnes technique does not work well for quality control of fine-resolution data in complex terrain, because any one surface observation might not be represented well by nearby observations at different elevations or on the opposite side of a mountain range. In steep terrain, the observation-to-background difference might be large due to a discrepancy between the actual station elevation and the model GP elevation, rather than due to bad quality of the surface observation. We have reduced the ADAS trilinear interpolation to bilinear when the first-guess fields are interpolated to the observation locations. The ADAS trilinear interpolation algorithm causes large interpolation errors by introducing "free-atmosphere" background values (Lazarus et al. 2002); also, the algorithm causes large extrapolation errors for the surface valley stations far below the lowest model level.

Because the objective quality-control methods are problematic in steep mountains, we instead do subjective examinations on observation minus background residuals (not shown).

\section{3) Anisotropic CORrelation FUnCtion}

The ADAS Bratseth scheme works iteratively, updating the first guess using the difference between the observed values and observational estimates derived from the analysis (CAPS 1995; Lazarus et al. 2002). The optimum Bratseth weights rely on the correlation $(\rho)$ of the background errors (and on the ratio of observation error variance to background error variance). Over flat terrain, a Gaussian function $[G(d)]$ is frequently used to smoothly reduce the correlation with distance $(d)$, causing the impact of a single observation to be isotropic in the grid space around the observation $[\rho(d) \propto G(d)]$.

In mountainous terrain, we modify the Gaussian drop-off to be a function of the CTD ( $s$, defined in section 4) from the observation to an analysis point $[\rho(s) \propto G(s)]$. As discussed in section 1, the correlation should be weighted by an anisotropic term $(S)$ that is a function of the difference between elevations of the observation $\left(Z_{o}\right)$ and the analysis point $\left(Z_{a}\right)$. By separating horizontal and vertical effects into two factors, an anisotropic correlation becomes

$$
\rho(s)=G(s) \times S\left(Z_{o}, Z_{a}\right) .
$$

An MD approach is proposed in section 4 to generate $S$ and $s$ for each observation station. This approach is based on first-order BL characteristics in mountainous terrain, described next.

\section{Topographic anisotropy and boundary layers}

\section{a. First-order boundary layer characteristics in mountainous terrain}

Atmospheric BLs always contain air of colder potential temperature than the air higher in the free atmosphere (FA), because the average troposphere is stably stratified (Stull 1988, 2000). Between the BL and FA is a strongly stable layer that caps the BL. Trapped in the BL below this cap are pollutants, humidity, and heat released from the surface.

In steep mountains, the ridge heights above valley floors are frequently the same order as BL heights. To a zeroth order, the turbulent and advective communication of physical, dynamic, and chemical states between one valley and the other depends greatly on whether the $\mathrm{BL}$ is shallower than the surrounding ridges. For shallow BL situations, tracers emitted into one valley $\mathrm{BL}$ are unlikely to reach neighboring valleys, due to blocking by mountains. For situations with BLs deeper than ridges, BL air can mix between neighboring valleys.

To a first order, the BL top $\left(z_{i}\right)$ is often not level over complex terrain. Observations show a variety of behaviors, ranging from BLs that follow the topography to BLs that seem relatively level (Lenschow et al. 1979; De Wekker et al. 1997; Kalthoff et al. 1998; Kossmann et al. 1998). Stull (1992) identified four archetypical BL-top characteristics (Fig. 1). Gravitational forces tend to make a level BL top (Fig. 1c), much like an ocean surface that is level over undersea mounts. Other factors including entrainment, advection, and friction tend to make a terrain-following top (Fig. 1b). See Stull (1998) for a similarity-theory analysis of the competing factors. We will focus on the level and terrain-following cases (Fig. 2).

BL parameterizations in most NWP models do not provide information on levelness of the BL top within first-guess fields for use during data assimilation. Nor are observations of BL depth usually available at every surface weather station. In an attempt to compensate for the lack of information, we develop a background error correlation $(\rho)$ that includes weighting factors for both "level-top" and terrain-following BL effects. Namely, we define the sharing factor SF $[S$ in (1)] during one iteration by 

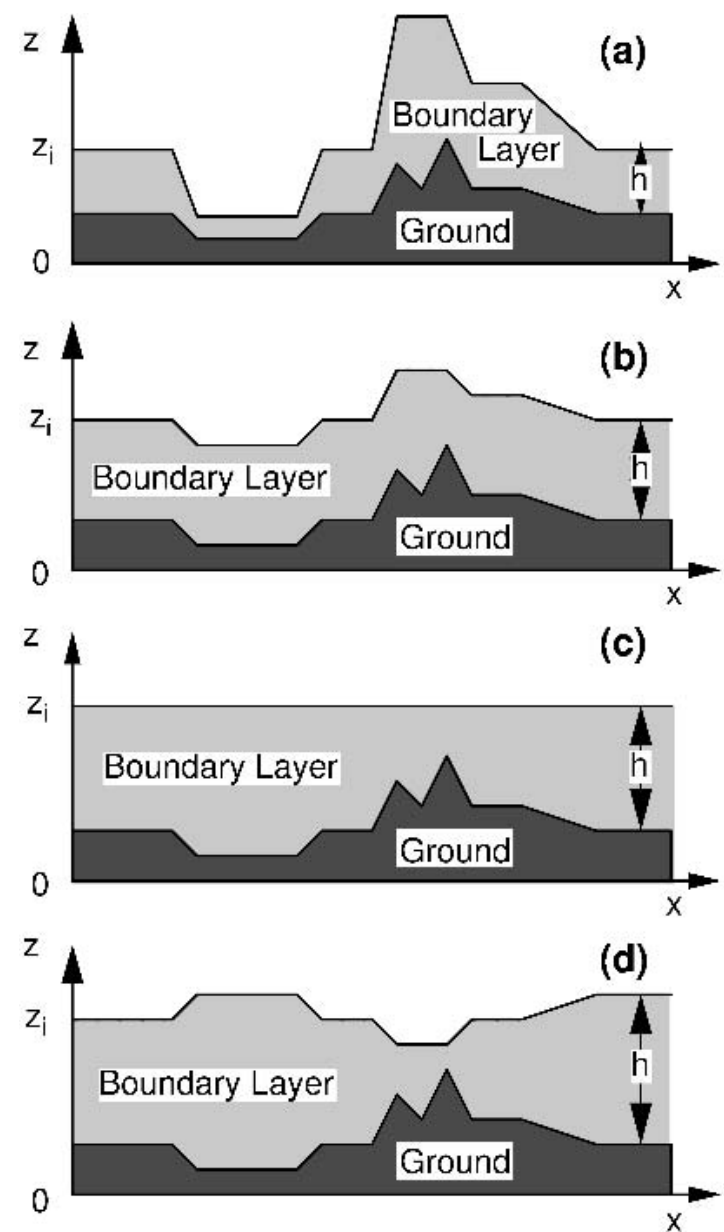

FIG. 1. Archetypical categories of mixed-layer-top levelness (after Stull 1992). (a) Hyper terrain following; (b) terrain following; (c) level; (d) contra-terrain following.

$$
\begin{aligned}
S_{o d}(\nu+1)= & S_{\text {om }}(\nu) \times W_{\mathrm{TFBL}}(\nu+1, \nu) \\
& \times W_{\mathrm{LTBL}}(\nu+1),
\end{aligned}
$$

where subscript $o$ represents the observation, subscripts $m$ and $d$ represent a GP (mother) and its neighboring GP (daughter), respectively. Weights $W$ represent the portions of the SF associated with terrain-following BLs (TFBLs) or level-top BLs (LTBLs).

\section{b. Parameterization of terrain-following and level-top BL contributions}

Let $Z$ be elevation. Approximate the terrainfollowing $\mathrm{BL}$ effects on the SF, from one mother GP during iteration $\nu$ to a neighboring daughter GP at iteration $\nu+1$, by

$$
W_{\mathrm{TFBL}}(\nu+1, \nu)=1-\left[\frac{\left|Z_{m}(\nu)-Z_{d}(\nu+1)\right|}{\operatorname{zref} 1}\right]^{a}
$$

for $\left|Z_{m}(\nu)-Z_{d}(\nu+1)\right|<$ zref1; otherwise $W_{\text {TFBL }}=0$. The terrain-following BL-depth parameter is zref1,
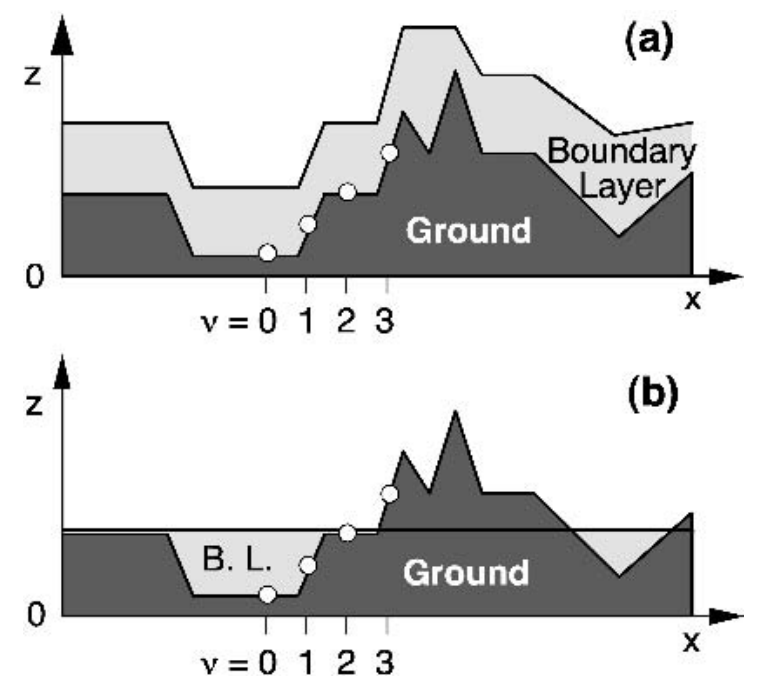

FIG. 2. Shallow boundary layers in steep terrain, for (a) a terrain-following boundary layer and (b) a level-top boundary layer blocked by mountains. White dots represent surface grid points. The iteration counter $\nu$ coincides with each successive daughter grid point. The lowest grid point at $\nu=0$ is collocated with the surface weather station.

while parameter $a$ controls the analysis decorrelation rate.

For illustration, suppose that zref1 $=1 \mathrm{~km}$ and $a=1$. Let the weather station be collocated with a model GP (the first mother GP) at the base of linearly sloping terrain (Fig. 2a) such that each successive daughter GP is higher up the slope: $z(\nu)=0,0.5,1.0,1.5 \mathrm{~km} \ldots$ for $\nu=0,1,2,3 \ldots$ The iteration counter $(\nu)$ coincides with each successive daughter GP. The resulting sequence of weights from (3) is $W_{\mathrm{TFBL}}=1.0,0.5,0.5$, and 0.5 . These weights accumulate multiplicatively via the iteration given by (2). Considering only terrainfollowing effects, $S(0)=1, S(1)=0.5, S(2)=0.25$, and $S(3)=0.125$. The GP at $Z=1.5 \mathrm{~km}$ has nonzero SF, for the case of a terrain-following 1-km-thick BL, where turbulence can mix valley variables up the mountain slope.

Similarly, we can define a level-top BL weight by

$$
W_{\mathrm{LTBL}}(\nu+1)=1-\left[\frac{\left|Z_{o}-Z_{d}(\nu+1)\right|}{\operatorname{zref} 2}\right]^{b}
$$

for $\left|Z_{o}-Z_{d}(\nu+1)\right|<$ zref2; otherwise $W_{\text {LTBL }}=0$. The level-top BL-depth parameter is zref2, while parameter $b$ controls the analysis decorrelation rate.

For illustration with the same sloping GPs as in the previous example, suppose that zref $2=1 \mathrm{~km}$ and $b=$ 1 . The resulting sequence of weights from (4) is $W_{\mathrm{LTBL}}$ $=1.0,0.5,0$., and 0 . These weights accumulate multiplicatively via iteration as in (2). If we neglect the terrain-following effects, $S(0)=1, S(1)=0.5, S(2)=0$., and $S(3)=0$. The GP at $Z=1.5 \mathrm{~km}$ has zero SF, because it is above the level BL top (Fig. 2b). At all 
higher-elevation GPs, the SF is also zero. Those points higher on the mountain are assumed to be in a different air mass than the valley station. It is worth noting that zref2 is essentially the BL depth at the observation location. It will be shown later in the appendix that analysis results are far more sensitive to zref2 than to zref1.

These illustrations, albeit somewhat primitive, represent basic BL characteristics in a way that allows anisotropic correlations to be created, as shown next.

\section{The mother-daughter approach}

\section{a. General concepts}

We first consider a surface observation that happens to lie directly on a model GP. The fraction of information shared between the observation and any analysis point is called "sharing factor" (SF), which ranges between 0 and 1 . Let subscripts $o, m$, and $d$ represent an observation, a mother GP and a neighboring daughter GP, respectively. The iterative MD approach is expressed by

$$
\begin{aligned}
S_{o d}(\nu+1)= & S_{o m}(\nu)\left\{1-\left[\frac{\left|Z_{m}(\nu)-Z_{d}(\nu+1)\right|}{\operatorname{zref} 1}\right]^{a}\right\} \\
& \times\left\{1-\left[\frac{\left|Z_{o}-Z_{d}(\nu+1)\right|}{\operatorname{zref} 2}\right]^{b}\right\} \\
& \text { if }\left|Z_{m}(\nu)-Z_{d}(\nu+1)\right|<\operatorname{zref} 1 \\
& \text { and }\left|Z_{o}-Z_{d}(\nu+1)\right|<\operatorname{zref} 2 \\
S_{o d}(\nu+1)= & 0 \text { if }\left|Z_{m}(\nu)-Z_{d}(\nu+1)\right| \geq \operatorname{zref} 1 \\
& \text { or }\left|Z_{o}-Z_{d}(\nu+1)\right| \geq \operatorname{zref} 2
\end{aligned}
$$

where $\nu$ is iteration counter; $Z$ is elevation; and $a, b$, zref1, and zref2 are free parameters. The amount of information that a mother transfers to each daughter is reduced by the elevation difference between them. The iteration starts with $S_{o m}(0)=1$ at the surface observation location. As previously discussed, the first and second bracketed terms in Eq. (5a) contain the terrainfollowing $\left[W_{\text {TFBL }}\right.$ in Eq. (3)] and level-top $\left[W_{\mathrm{LTBL}}\right.$ in Eq. (4)] BL effects, respectively.

The observation is treated as the first mother, who has daughters at each of her eight neighboring GPs. This is the first iteration $(\nu=1)$. These daughter SFs are calculated by applying (5) to every motherdaughter pair. The circuitous travel distance from the observation to a neighboring daughter GP, after $\nu=1$, is equal to the straight-line horizontal distance if the SF at that daughter GP is not zero. For zero SF, the CTD is assigned a large value $(s=1.0 \mathrm{e} 5 \mathrm{~km})$, so that $\rho(s)$ in (1) is zero due to the Gaussian drop-off. Namely, the observation has no influence on that GP. Next, every daughter becomes a mother and has her own eight daughters around her, and so on (see below). Around any daughter might be several mothers who contribute different SFs to that daughter, but only the biggest SF (among all values from neighboring mothers and the value from the previous iteration) is kept. Thus, Eq. (5) has to be applied successively to every GP within a gradually enlarged subdomain centered at the observation location. This process is computationally expensive, as demonstrated in section 6b. From the second iteration onward, the CTD from the observation to any daughter GP is found by accumulating the incremental path segments from each successive mother to the daughter GP. Usually there are many different paths from the observation to a distant GP, but the path saved is the one with the largest SF at that daughter GP. Figure 3 illustrates the CTD $(s)$ from the observation "O" to GP "D."

To illustrate calculations of the SFs and CTDs, consider a surface station that happens to lie directly on a model GP at $(x, y)=(7,5)$ (Figs. 4 and 5, indicated by a solid triangle). Horizontal grid spacing is $3 \mathrm{~km}$. Initially, the SF is 1.0 at the observation location, and zero elsewhere (left-hand panel of Fig. 4a). The CTD is initially $0 \mathrm{~km}$ at the observation point and $1.0 \mathrm{e} 5 \mathrm{~km}$ otherwise (right-hand panel of Fig. 4a). The SFs and CTDs after the first iteration are shown in Fig. 4b. The CTD for a daughter GP remains $1.0 \mathrm{e} 5 \mathrm{~km}$ if its SF is 0 . Thus, the CTD $(s)$ from the observation to the GP at $(8,5)$ is $1.0 \mathrm{e} 5 \mathrm{~km}$, even though the straight-line horizontal distance $(d)$ is $3 \mathrm{~km}$. A daughter GP with nonzero SF has finite CTD [e.g., $s=d \approx 4.2 \mathrm{~km}$ for GP $(6,6)$ ]. In the second iteration, each daughter becomes a mother and has her own eight daughters around her, yielding 24 $(8+16)$ daughters after $\nu=2$ (Fig. 4c). This process is repeated until $\left|S_{o d}(\nu+1)-S_{o d}(\nu)\right|<0.01$ for all GPs. The final SFs $\left(S_{o d}\right)$ and CTDs $(s)$ are used in (1) to determine the anisotropic correlation function $[\rho(s)]$. Figure 5 shows the end results for this hypothetical sta-

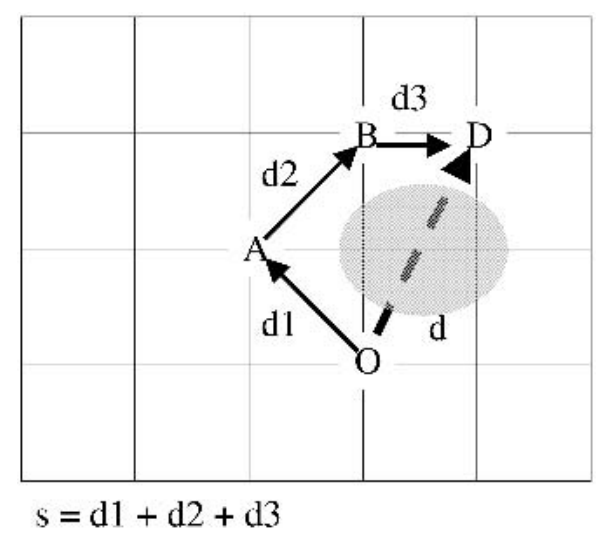

FIG. 3. Schematic of the straight-line horizontal distance $(d)$ and the circuitous travel distance $(s=d 1+d 2+d 3)$ from the observation location $\mathrm{O}$ to the grid point $\mathrm{D}$, after the third iteration. The grid point $D$ received the most contribution in its sharing factor from the grid point $\mathrm{B}$, while the grid point $\mathrm{B}$ received the most contribution from the grid point $\mathrm{A}$ that received the most contribution from the observation $\mathrm{O}$. This illustrates a situation such as when a mountain (indicated by shading) lies between $\mathrm{O}$ and $\mathrm{D}$. 

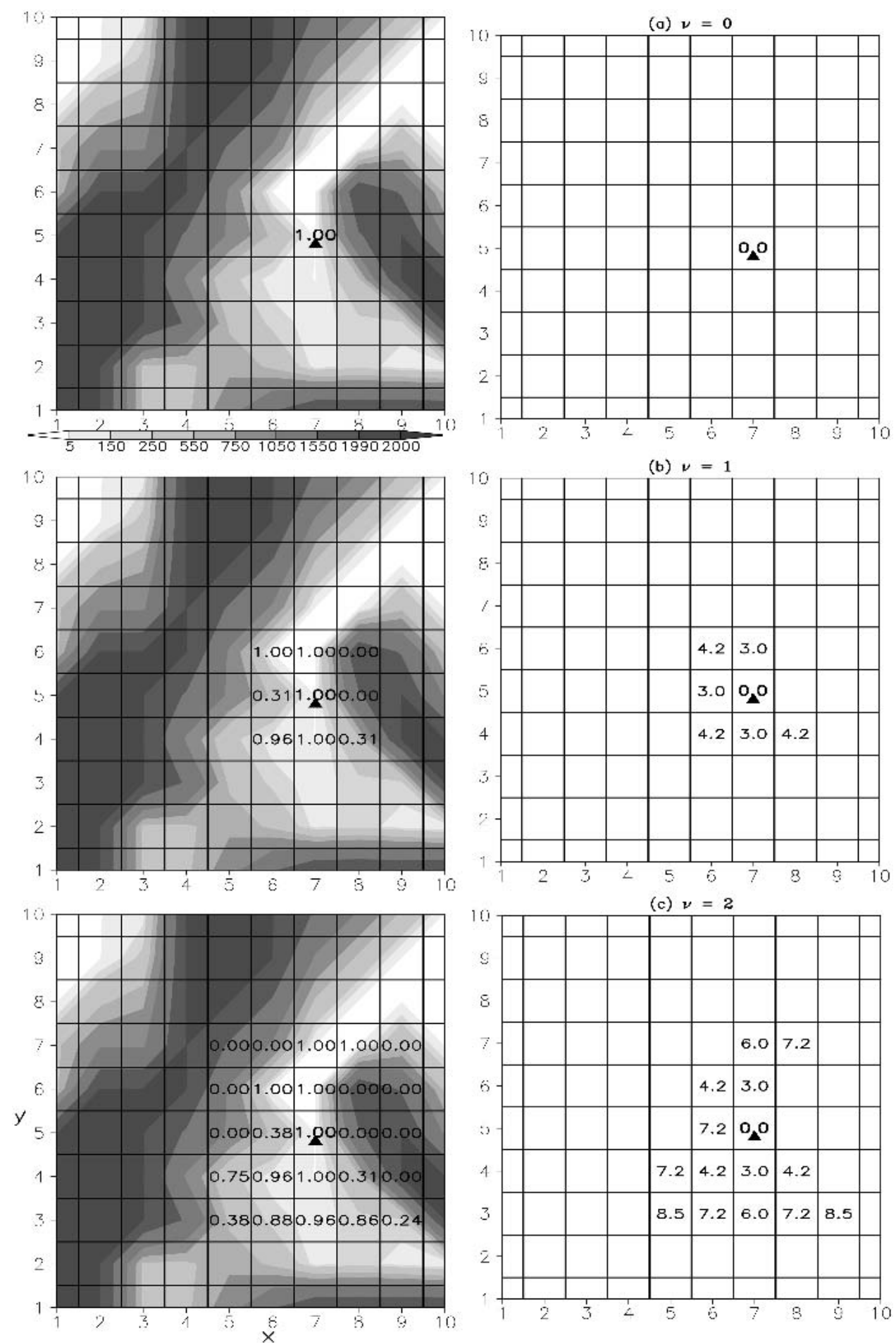

FIG. 4. (left column) Printed values of the sharing factors (zeroes are not printed except when they first appear in an iteration; darker shading indicates higher elevations) and (right column) circuitous travel distance $(\mathrm{km})$ (large values of $1.0 \mathrm{e} 5$ are not printed). (a) iteration counter $\nu=0$; (b) $\nu=1$; (c) $\nu=2$. The observation is indicated by a solid triangle at $(x, y)=(7,5)$. Grid spacing is $3 \mathrm{~km}$. The parameters used are $a=2, b=2$, zref1 $=750 \mathrm{~m}$, and zref $2=750 \mathrm{~m}$. Grid cells along the outside edge are cut off in this plot but are really the same size as all other grid cells. 

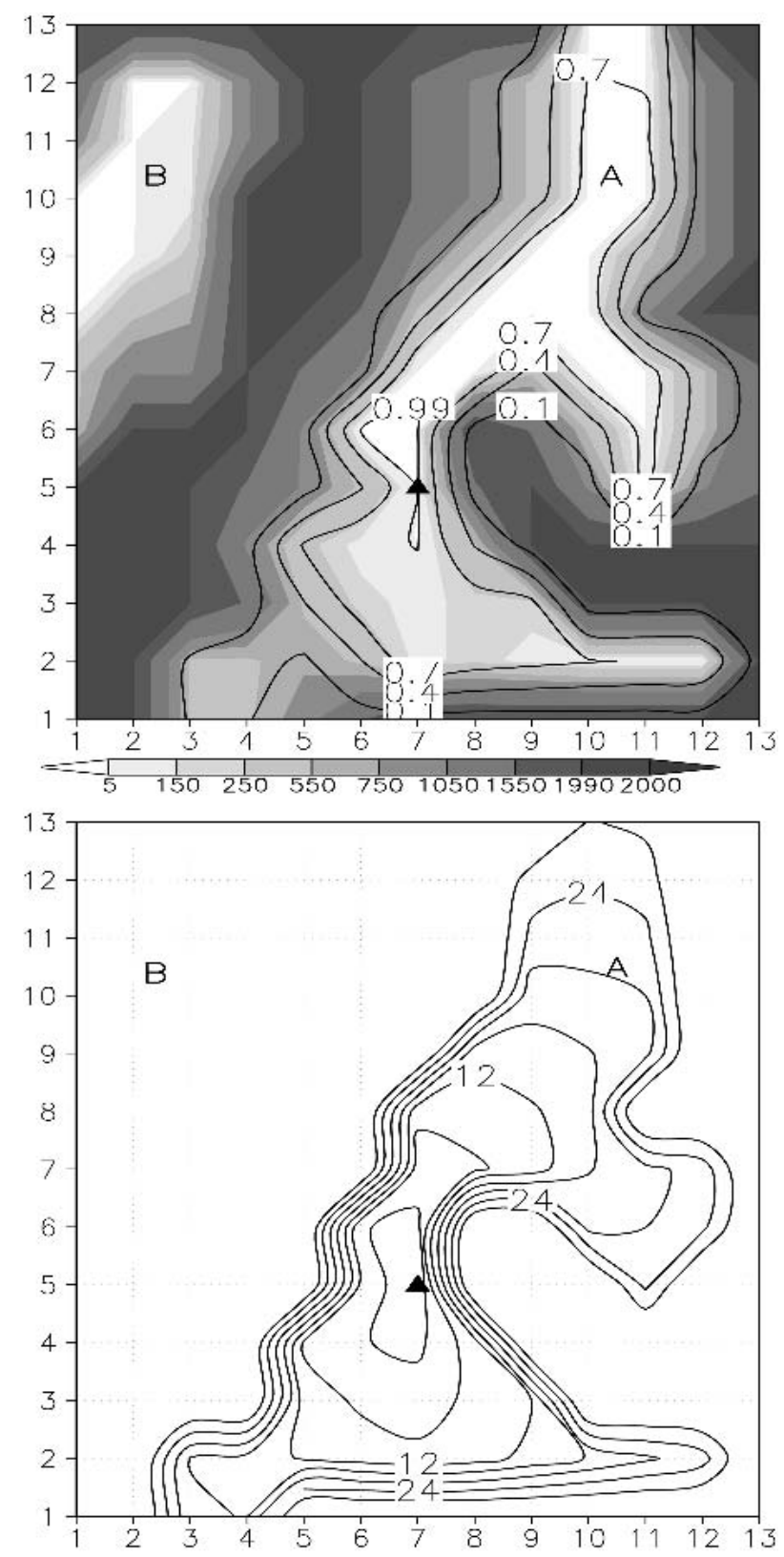

FIG. 5. (top) Sharing factor isopleths (thin lines, after a Gaussian drop-off with standard deviation of $30 \mathrm{~km}$ ) and (bottom) the circuitous travel distance $(\mathrm{km})$ for an idealized observation in valley A within a horizontal domain that spans $36 \mathrm{~km} \times 36 \mathrm{~km}$ with a grid increment of $3 \mathrm{~km}$. Terrain elevations $(\mathrm{m})$ are shown by shading in the top plot. Darker shading indicates higher elevations, with a maximum terrain-height difference of $2000 \mathrm{~m}$. The observation is indicated by a solid triangle at $(x, y)=(7,5)$. The parameters used are $a=2, b=2$, zref1 $=750 \mathrm{~m}$, and zref $2=750 \mathrm{~m}$.

tion, using a Gaussian drop-off with a standard deviation of $30 \mathrm{~km}$.

To examine the subtleties of the CTD, consider GP $(6,5)$ in Fig. 4. After $\nu=1, S=0.31$ and $s=3 \mathrm{~km}$ (Fig. $4 \mathrm{~b})$. Obviously, the SF comes from the first mother (i.e., the observation). After $\nu=2, S=0.38$ and $s \approx 7.2 \mathrm{~km}$
(Fig. 4c). Now the largest SF comes from a secondgeneration mother GP $(6,4)$. The CTD $(s \approx 7.2 \mathrm{~km})$ equals the sum of $d \approx 4.2 \mathrm{~km}$ between the observation and the second-generation mother GP $(6,4)$, plus $d=$ $3 \mathrm{~km}$ from GP $(6,4)$ to the target GP $(6,5)$.

Parameters $a$ and $b$ in (5) control SF reduction by the mother-daughter GP elevation difference. As $a$ and $b$ are reduced from 4 toward 1 , the terrain effects on the analysis increase. The optimum values of $a, b$, zref1, and zref2 can be obtained by analyzing a subset of the available observations, and verifying against the remaining observations for a substantial period of daily analyses, assuming a dense observation network.

For fixed GPs and observation locations within a model domain, the SFs and CTDs for each observation station can be determined. In the case of a surface observation station that is not collocated with a model GP, the station is first approximated as being collocated at the nearest neighboring model GP with minimum elevation difference between them. The resulting SFs and CTDs are saved as a fixed file, which can be applied unchanged for each day's analysis to efficiently determine the correlation in the ADAS Bratseth scheme. In the presence of temporally missing observations, a flag (i.e., -999.) can be assigned to the missing observations. The SFs and CTDs for a newly added surface station can be calculated and appended to the fixed file.

\section{b. Refinement for coastal terrain}

To consider land-sea contrasts, Hessler (1984) estimated two correlation functions from surface temperature statistics near the Baltic Sea. Between pairs of sea stations or pairs of land stations, he approximated correlations by $\exp \left(-0.08 d^{0.13}\right) \cos (0.4 d)$. Between sea and land stations, he used $\exp \left(-0.29 d^{0.06}\right) \cos (0.2 d)$.

We introduce a similar approach by including an additional factor (i.e., the third term in brackets on the right-hand side):

$$
\begin{aligned}
S_{o d}^{\mathrm{LS}}(\nu+1)= & S_{\text {om }}^{\mathrm{LS}}(\nu)\left\{1-\left[\frac{\left|Z_{m}(\nu)-Z_{d}(\nu+1)\right|}{\mathrm{zref} 1}\right]^{a}\right\} \\
& \times\left\{1-\left[\frac{\left|Z_{o}-Z_{d}(\nu+1)\right|}{\mathrm{zref} 2}\right]^{b}\right\} \\
& \times\left\{1-\frac{\left|\mathrm{LS}_{o}-\overline{\mathrm{LS}_{d}(\nu+1)}\right|}{K_{\mathrm{LS}}}\right\}
\end{aligned}
$$

for $\left|Z_{m}(\nu)-Z_{d}(\nu+1)\right|<$ zref1 and $\left|Z_{o}-Z_{d}(\nu+1)\right|$ $<$ zref2; otherwise $S_{o d}^{\mathrm{LS}}(\nu+1)=0$. The land-sea mask $\mathrm{LS}_{o}$ at the observation location is equal to one for a land observation and zero for a water observation. The land-sea mask $\overline{\mathrm{LS}_{d}}$ at a daughter GP is similar, but averaged over the nine GPs immediately around and including the daughter GP. The average allows gradual transition of the SFs across the coastlines in an attempt to slightly account for sea/land breeze effects. Parameter $K_{\mathrm{LS}}$ controls the degree of the decorrelation be- 
TABLE 1. Experiments performed, where $R_{h}$ and $R_{z}$ are correlation length scales in the horizontal and vertical, respectively, which define the regions of influence; $d_{i j}$ and $\Delta z_{i j}$ are straight-line horizontal distance and elevation difference between an analysis grid point and the observation station, respectively; $K_{z}$ is a coefficient; $s_{i j}$ is the circuitous travel distance from the observation to an analysis grid point determined in the mother-daughter program; $S_{o d}$ is the sharing factor at an analysis grid point, which represents how much the analysis grid point shares the observation information; $S_{o d}^{\mathrm{LS}}$ is the same as $S_{o d}$ except that the former is from the refined mother-daughter approach. In this study, $R_{h}$ is $90 \mathrm{~km}$ for the first and second iterations, $60 \mathrm{~km}$ for the third iteration, and $30 \mathrm{~km}$ for the fourth and fifth iterations, during the ADAS assimilation cycle.

\begin{tabular}{lc}
\hline \hline Experiment & Correlation function $(\rho)$ \\
\hline GAUSS & $\exp \left(-\frac{1}{2} \frac{\left|d_{i j}\right|^{2}}{R_{h}^{2}}\right) \cdot \exp \left(-\frac{1\left|\Delta z_{i j}\right|^{2}}{R_{z}^{2}}\right)$ \\
TERR_DIFF & $\exp \left(-\frac{1}{2} \frac{\left|d_{i j}\right|^{2}}{R_{h}^{2}}\right) /\left(1+K_{z} \cdot\left|\Delta z_{i j}\right|^{2}\right)$ \\
MD & $\exp \left(-\frac{1}{2} \frac{s_{i j}^{2}}{R_{h}^{2}}\right) \cdot S_{\text {od }}$ \\
MD_LSMG & $\exp \left(-\frac{1}{2} \frac{s_{i j}^{2}}{R_{h}^{2}}\right) \cdot S_{\text {od }}^{\mathrm{LS}}$ \\
\hline
\end{tabular}

tween land stations and analysis points over water, or between water stations and analysis points over land; $K_{\mathrm{LS}}$ was subjectively set to 1.0 for the case studies in section $6 \mathrm{~b}$, but could be greater than 1.0 for strong sea-breeze events.

Ideally, the location of the land-sea mask should shift as the sea/land breezes evolve every day; however, we neglect this shift. This allows a computationally efficient constant land-sea mask that still captures firstorder effects.

\section{Numerical experiments}

Four assimilation experiments (Table 1) are performed for comparison purposes. GAUSS, the native scheme in the ADAS (ARPS5.0.0 Beta8), includes terrain effects with a Gaussian function of elevation difference $(\Delta z)$ between the GP and observation station, and horizontal Gaussian decay to define the region of influence. In experiment TERR_DIFF, the Miller and Benjamin (1992) method is added to the ADAS, but slightly modified from the original correlation function ${ }^{2}$ for potential temperature used in Miller and Benjamin (1992).

In experiment MD, the SFs from Eq. (5) are used to replace the Gaussian elevation term in GAUSS. MD further differs from GAUSS and TERR_DIFF by using the CTD, rather than the straight-line horizontal dis-

\footnotetext{
$2 \exp \left(-|d|^{2} / 2 r^{2}\right) /\left(1+K_{z} \cdot|\Delta z|^{2}\right), r=300 \mathrm{~km}, K_{z}=7 \times$
$10^{-7} \mathrm{~m}^{-2}$
}

tance, in the horizontal part of the correlation function. This effectively limits the region of influence in complex terrain and restricts valley observation information to follow the valleys around the ridges, while reducing spread over the ridge top. Similarly, ridge-top information follows ridges, with little spread into valleys. MD_LSMG is the same as MD except that land-sea anisotropy is included in the SFs (section 4b).

Unless stated specifically, the horizontal correlation length scale $\left(R_{h}\right)$ is $90 \mathrm{~km}$ for the first and second Bratseth passes, $60 \mathrm{~km}$ for the third pass, and $30 \mathrm{~km}$ for the fourth and fifth passes.

\section{Case studies}

The utility of the MD approach is demonstrated below for surface potential-temperature analyses in two regions. Virtual and real observations are used for mountainous and coastal terrains, respectively, in southwestern BC.

\section{a. Virtual observations}

We first use "fraternal-twin" experiments to evaluate the MD approach in mountainous terrain. In fraternaltwin experiments, the "truth" and "analysis" models are similar, but not identical (Arnold and Dey 1986). The truth model (MC2 at 2-km grid spacing) is first integrated $12 \mathrm{~h}$ to generate a reference truth atmosphere. To generate a different first guess, the analysis model (MC2 at $3 \mathrm{~km}$ with radiation turned off to purposely introduce errors) is integrated $12 \mathrm{~h}$ with the same boundary conditions, but using perturbed initial conditions. Amplitudes of random perturbations for temperature ( $u$ wind, $v$ wind, logarithm of pressure perturbation, specific humidity) are $5.0^{\circ} \mathrm{C}(5.0 \mathrm{kt}, 5.0 \mathrm{kt}$, $0.0005,0.005 \mathrm{~kg} \mathrm{~kg}^{-1}$ ). A dynamic initialization algorithm built into MC2 is activated for the $3-\mathrm{km}$ run to remove spurious gravity waves excited by the added perturbations.

The fraternal-twin experiments are performed for 7-8 March 2003, characterized by an Arctic outbreak, when cold shallow air masses from northern Canada swept into the valleys in $\mathrm{BC}$.

The MC2 runs consist of five self-nested grids with grid spacings of $108,36,12,4$, and 2 or $3 \mathrm{~km}$ (see the last three grids in Fig. 6). The Eta analysis and forecasts at 90.7-km grid spacing from the National Centers for Environmental Prediction (NCEP), valid at 0000 UTC 7 March 2003, are used as the initial and boundary conditions for the coarsest grid. The MC2 at $2 \mathrm{~km}$ is started at 1200 UTC 7 March from MC2 4-km output and integrated $12 \mathrm{~h}$ to generate the truth atmosphere, from which virtual surface observations are extracted. All virtual observations are assumed to be perfect, with zero observation error. The MC2 at $3 \mathrm{~km}$ is also started at 1200 UTC 7 March, but from the randomly perturbed output of the $4-\mathrm{km}$ run, and integrated $12 \mathrm{~h}$ to 


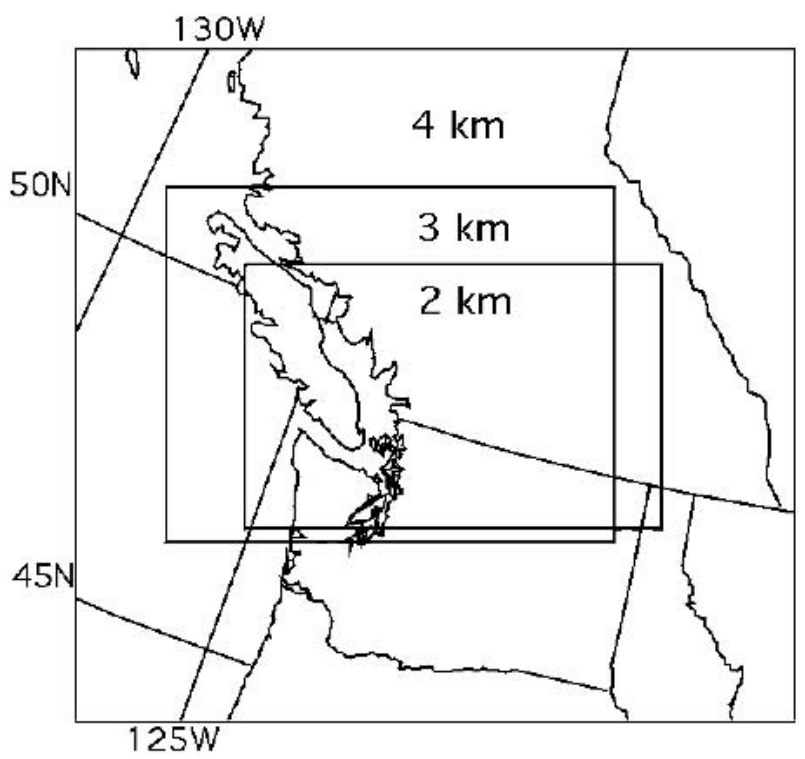

FIG. 6. MC2 grid domains for 4, 3, and $2 \mathrm{~km}$. MC2 4-km output provides nesting files to initialize $2-$ and $3-\mathrm{km}$ runs. MC2 $2 \mathrm{~km}$ is run to provide a reference atmosphere to generate virtual surface observations for analysis and verification. MC2 $3 \mathrm{~km}$ is run to provide first-guess fields for analysis.

provide a first guess. The analyses are performed at the lowest terrain-following model level of the MC2 $3 \mathrm{~km}$ at 0000 UTC 8 March.

Figure 7 shows six virtual surface stations. Stations o1 (elevation $920 \mathrm{~m}$ ) and o2 (elevation $536 \mathrm{~m}$ ), located in different valleys, are used for analysis. Station o1 is in the Elaho River Valley, and o2 is in the Lillooet River
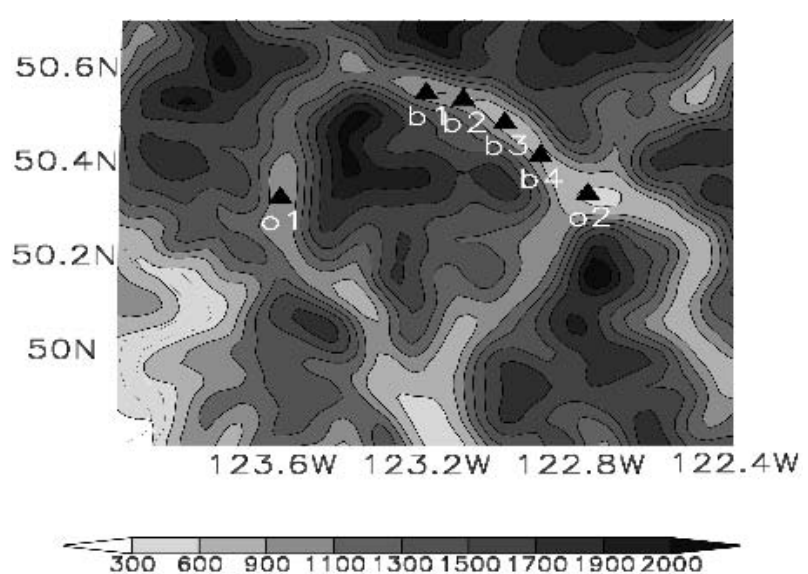

FIG. 7. Virtual surface observation stations, indicated by solid triangles, used in the analysis and verification. The stations are positioned at the truth-model terrain height in the Coast Mountains north of Vancouver. Station o1 $\left(50.326^{\circ} \mathrm{N}, 123.578^{\circ} \mathrm{W}\right)$ is near the mouth of the Elaho River. Station o $2\left(50.3344^{\circ} \mathrm{N}\right.$, $\left.122.767^{\circ} \mathrm{W}\right)$ is near the town of Pemberton. Terrain elevations (m) are from the truth model. Darker shading indicates higher elevations, with a maximum elevation difference of $2055 \mathrm{~m}$ in this figure.
Valley. Four stations (b1, b2, b3, and b4) in the Lillooet River Valley are used for verification. These stations are selected to evaluate the impact of observation o1 on the neighboring Lillooet River Valley. Elevations for stations b1, b2, b3, and b4 are 894, 881, 765, and $830 \mathrm{~m}$, respectively.

\section{1) IMPACT OF A SINGLE VALLEY SURFACE OBSERVATION}

For objective analysis, the interpolated first guess is usually subtracted from the observation to give an "observation increment," which is analyzed to produce "analysis increments" (AIs) at the GPs. The final analysis at each GP is then the first guess plus the analysis increment. The AIs produced by o1 show how data are spread to surrounding GPs.

Figure 8 shows the impact of o1 on the GP analysis. The observation increment is $-3.35 \mathrm{~K}$. The Bratseth analysis is confined to a single pass for convergence in the presence of a single perfect observation. All experiments show that the observation mostly influences the valley GPs.

GAUSS and TERR_DIFF both yield large AIs in valleys disconnected from the Elaho River Valley, even though both valleys may not necessarily share the same air mass. The Lillooet River Valley (containing b1, Fig. 7) is such an example. In MD, the large AIs are in the Elaho River Valley (containing o1), with much smaller values in the Lillooet River Valley.

\section{2) IMPACT OF TWO SURFACE OBSERVATIONS FROM DIFFERENT VALLEYS}

The analysis at one GP using observations from adjacent but disconnected valleys, where each valley contains a different meteorological regime, is a problem in complex terrain. To examine this, consider two observations in different valleys (stations $\mathrm{o} 1$ and $\mathrm{o} 2$ in Fig. 7). The observation at o1 is $3.35 \mathrm{~K}$ colder than the first guess, while the observation at $\mathrm{o} 2$ is $3.36 \mathrm{~K}$ warmer. Four stations (b1, b2, b3, and b4) in the Lillooet River Valley are used to verify the analyses.

First, only the observation at $\mathrm{o} 2$ is used. To evaluate the three schemes, the GP analyses are interpolated to the four verifying stations (not collocated with any GP) by cubic polynomial interpolation. The root-meansquare error (rmse) between the observations and analyses at those sites are calculated. For comparison purposes, the parameters for GAUSS $\left(R_{z}=500 \mathrm{~m}\right)$, TERR_DIFF $\left(K_{z}=7.0 \times 10^{-6} \mathrm{~m}^{-2}\right)$, and MD $(a=2$, $b=2$, zref1 $=750 \mathrm{~m}$, zref2 $=750 \mathrm{~m}$ ) are chosen so that the three schemes produce similar rmses. The values of these parameters are kept fixed for all subsequent experiments.

Rmses for GAUSS, TERR_DIFF, and MD are $0.6179,0.6468$, and $0.6559 \mathrm{~K}$, respectively. Rmses for these three schemes are slightly greater than that between the observations and the first guess, which is 

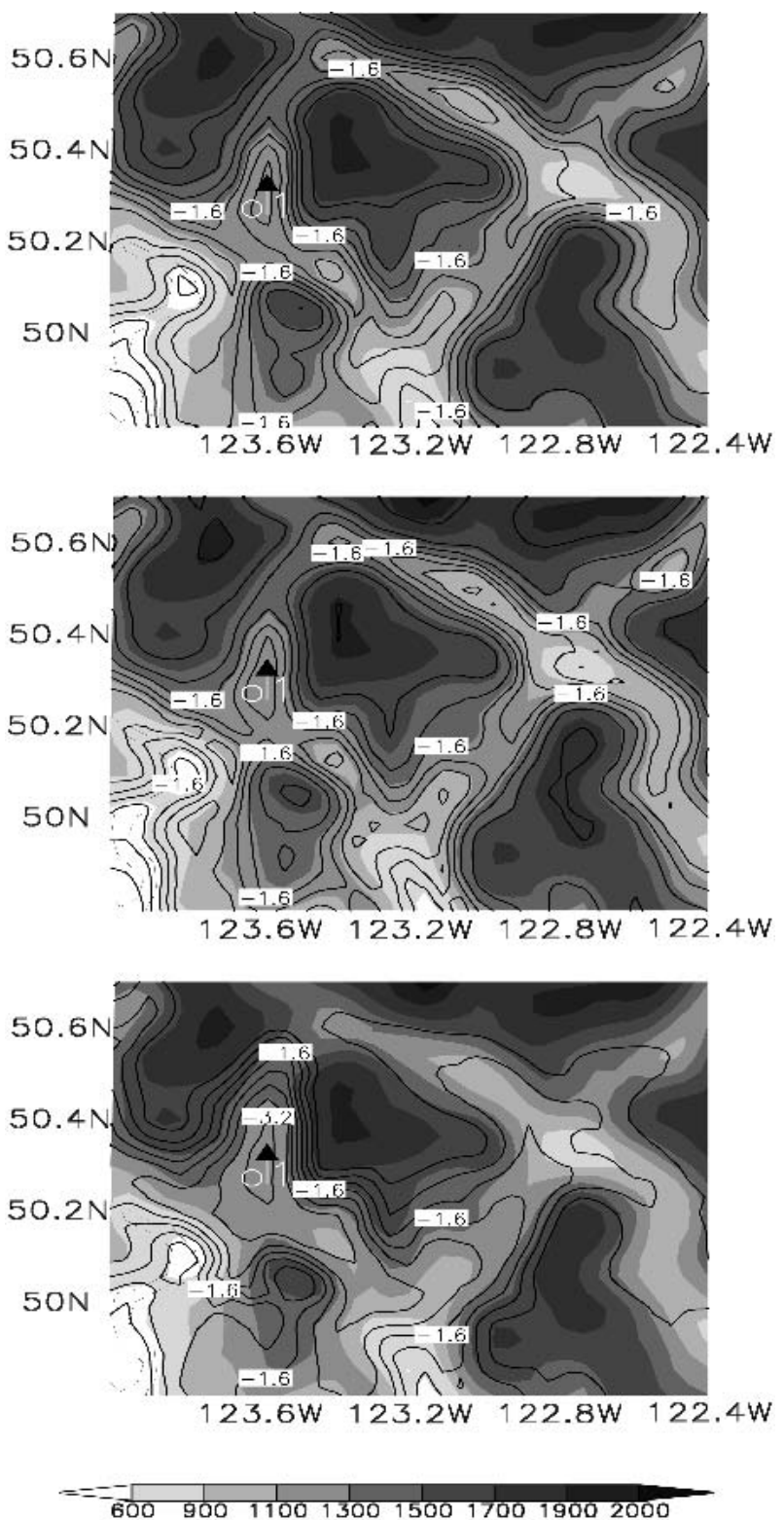

FIG. 8. Analysis increments (isopleths) for potential temperature at the lowest model level in response to a single surface potential-temperature observation at station o1 indicated by a solid triangle. Contour interval is $0.3 \mathrm{~K}$. Darker shading indicates higher elevations, with a maximum elevation difference of $1940 \mathrm{~m}$, which is less than that in Fig. 7 because of the smoothed terrain used in the NWP model. (top) GAUSS; (middle) TERR_DIFF; (bottom) MD.

$0.5395 \mathrm{~K}$. The analyses and the first guess versus the observations for the three schemes are shown in the left-hand panel of Fig. 9. It is evident that the three schemes produce similar analyses.

The observations from both sites (o1 and o2) are then used to produce an analysis. While the same set of observations at b1, b2, b3, and b4 are used for verification. The additional observation at 01 has a negative impact on both the GAUSS and TERR_DIFF analyses (see the right-hand panel of Fig. 9). Rmse increases to $2.1464 \mathrm{~K}$ for GAUSS and $2.4380 \mathrm{~K}$ for TERR DIFF. However, in MD, the additional observation at o1 has a minor impact on the analysis at the verifying stations, as desired because the two valleys with observations are not strongly coupled. The slight influence from the added observation reduces the rmse to $0.4807 \mathrm{~K}$. The rmse with two observations is reduced about $11 \%$ from the first guess.

\section{3) IMPACT OF A SINGLE HIGH-ELEVATION SURFACE OBSERVATION}

In complex terrain, most surface observation sites are located in densely populated valleys. There are, however, some surface stations located at high elevations in the mountains, such as at ski areas and in subalpine forest ecosystems. This subsection examines the analysis impact of high-elevation observations.

Figure 10 shows the AIs produced by o3 (elevation $1954 \mathrm{~m}$ ). The observation increment is $-1.56 \mathrm{~K}$. All schemes produce minimal spread into valley GPs, with MD producing zero spread into the valleys.

For GAUSS and TERR_DIFF, the observation increment is spread to all of the surrounding high mountains, including those separated by deep valleys. In MD, the observation corrects the first guess only for those GPs on the same mountain as 03 . The GAUSS and TERR_DIFF analyses in Fig. 10 look more realistic than MD for two reasons. During shallow cold-air pooling events, the high-mountain tops are all penetrating into the free atmosphere, where they would experience the same weather. Second, during deep BL events with BL top above the mountain top, vigorous turbulence would also cause mixing across the valleys. In future work, we plan to modify MD to allow such spreading.

\section{b. Real observations}

The MD approach is also tested with real observations in the coastal terrain of the Georgia Basin, BC. Hourly data are combined from several agencies, including the BC Ministry of Transportation and Highways (MOTH), BC Ministry of Water Land and Air Protection (WLAP), Environment Canada (EC), and BC Hydro (HYDR). The higher density of observations over the Georgia Basin (Fig. 11) allows us to withhold some for verification (Table 2). The land-sea mask is based on the model-resolved coastlines. The ratio of observation-error variance to background-error variance is 0.08 as in Miller and Benjamin (1992). The low observation-to-background error implies that the observations are heavily weighted.

A 3-4 February 2003 case, characterized by a strong ridge over the Georgia Basin, is used to examine if weak land-sea thermal contrasts can be properly analyzed. Figure 12 shows the evolution of potential temperatures for several surface stations on land and water 


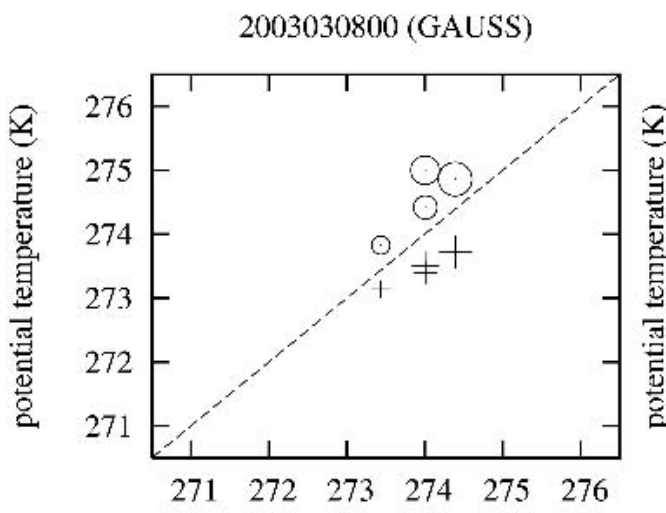

"observed" potential temperature $(\mathrm{K})$ 2003030800 (TERR_DIFF)

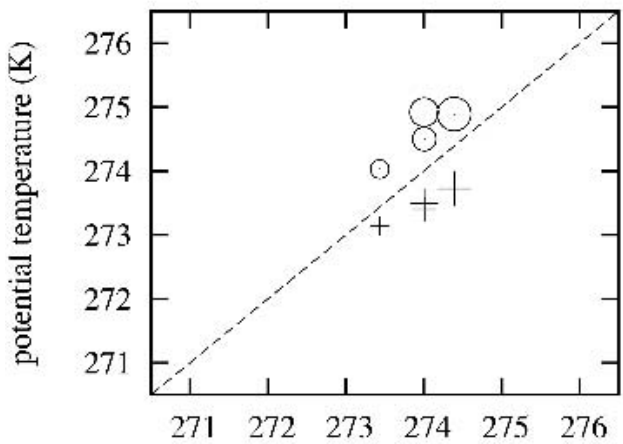

"observed" potential temperature $(\mathrm{K})$ 2003030800 (MD)

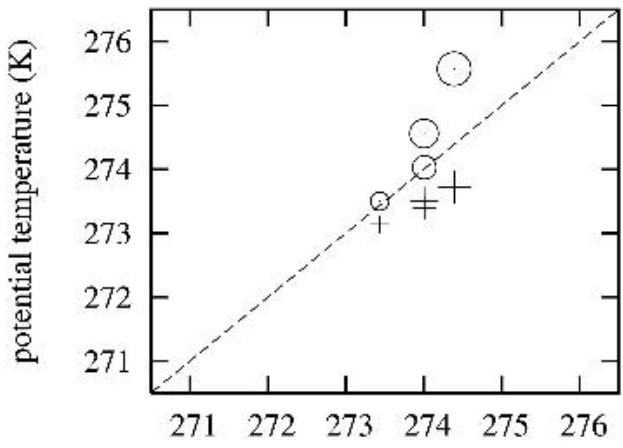

"observed" potential temperature (K)

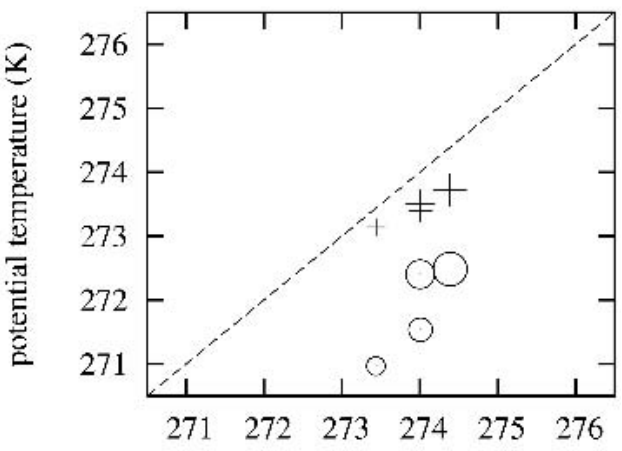

"observed" potential temperature (K) 2003030800 (TERR_DIFF)

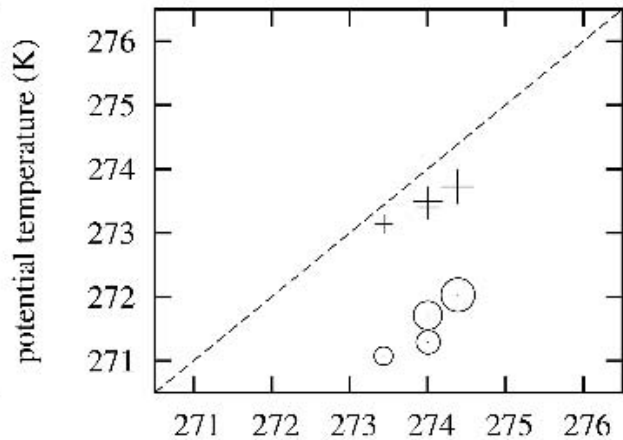

"observed" potential temperature (K) $2003030800(\mathrm{MD})$

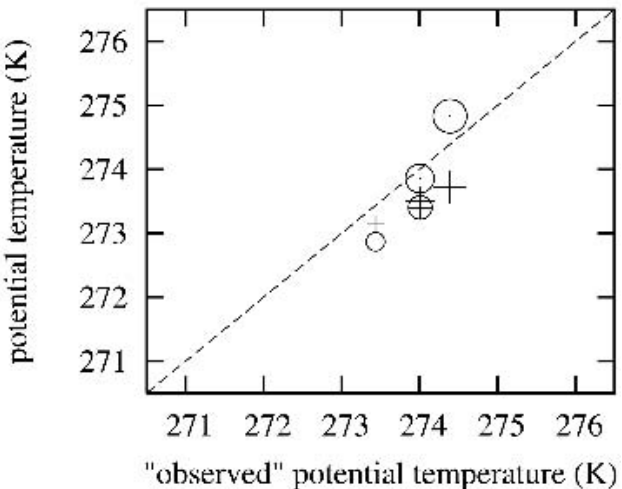

FIG. 9. Analysis, indicated by a circle, and first guess, indicated by a plus, vs observation. (left column) Observation at $\mathrm{o} 2$ only is used in the analysis. (right column) Observations at both o1 and o2 are used in the analysis. (top) GAUSS; (middle) TERR_DIFF; (bottom) MD. The four points (circles or pluses) correspond to the four verifying stations $\mathrm{b} 1-\mathrm{b} 4$.

during 0000-1200 UTC 4 February 2003. In late afternoon at 0000 UTC (1600 PST), all land stations except Vancouver INTL ARPT were slightly warmer than the water stations. After a transition period from 0100 to 0300 UTC, all land stations were colder than the water stations. Land-sea thermal contrast is the most prominent in early morning at 1200 UTC (0400 PST).

The Eta analysis and forecasts from NCEP, valid at
0000 UTC 3 February 2003, are used to drive the coarsest grid (108-km grid spacing), which in turn drives grids of 36,12 , and 4 or $3 \mathrm{~km}$. MC2 at $3 \mathrm{~km}$ provides first-guess fields and is started at 1200 UTC 3 February from MC2 4-km output. Analyses are performed every hour from 0000 to 1200 UTC 4 February, by blending hourly surface observations with the first guess at the lowest terrain-following model level valid at the same 

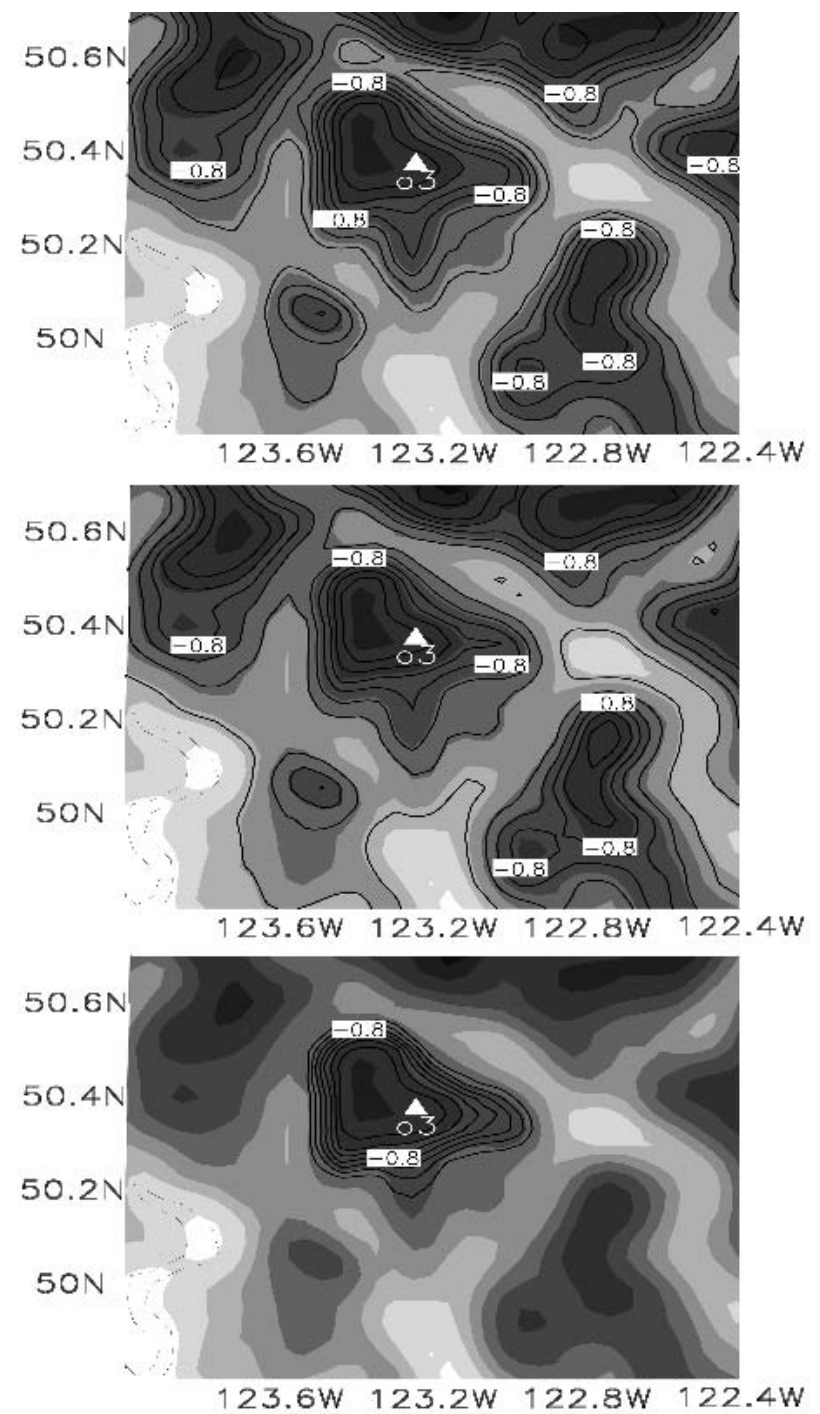

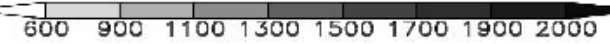

FIG. 10. Analysis increments (isopleths) for the potential temperature at the lowest (terrain-following) model level in response to a single high-elevation observation at $\mathrm{o} 3$, indicated by a white solid triangle on the mountain top. Contour interval is $0.2 \mathrm{~K}$. Darker shading indicates higher elevations (m). (top) GAUSS; (middle) TERR_DIFF; (bottom) MD.

time. The hourly analyses are not incorporated into the forecast cycle; thus, each analysis is independent of past observations. Eight stations are used for analysis and 11 others for verification (Table 2), but the available number of reporting stations varies with the analysis time (Table 3).

Figure 13 shows time series of the first guess (FSTG) or the analyzed potential temperature and observations for one water station (Entrance Island) and one land station (White Rock), separately. The 3-km run produces a good first guess for White Rock from 0300 to
1200 UTC 4 February, but underpredicts the potential temperatures for Entrance Island. The analyses from all experiments show more agreement with the observations than the first guess. Comparatively, MD and MD_LSMG both produce better analyses than GAUSS and TERR_DIFF. MD_LSMG is superior in maintaining the thermal contrast between Entrance Island and White Rock. Figure 14 further demonstrates advantages of MD_LSMG, based on separate averages from three land and three water stations. Averaging all land stations, including the mountain stations, makes the land-water contrast very small. However, advantages of MD_LSMG can be seen from separate averages of all water stations and all land stations except the mountain stations (not shown).

The verification statistics (Table 4) show that all schemes improve FSTG as measured by bias, mean absolute error (mae), and normalized root-mean-square error (nrmse). TERR_DIFF is slightly better than GAUSS, with smaller mae and nrmse. MD is better than GAUSS and TERR_DIFF, and MD_LSMG is the best. Percentage improvement of rmse over FSTG is below $40 \%$ for GAUSS and TERR_DIFF but above $50 \%$ for MD and MD_LSMG. Compared to MD, MD_LSMG gains 5\% more improvement.

To compare computational efficiency, each experiment is performed on one processor of a HighPerformance Computing Linux Super-Cluster, with 1-GHz Pentium III CPU. The results from a surfaceonly analysis at 0100 UTC 4 February 2003 are presented in Table 5. For the purpose of computational comparison, all 169 available temperature observations are used within a domain having $257 \times 205=52685$ GPs, with 3-km grid spacing. The execution time for GAUSS is slightly less than that for TERR_DIFF. The execution time for the MD approach is split into two parts: 1 ) the calculation of the SFs (which needs to be done only once for each surface station within an analysis domain, as mentioned in section 4a) and 2) the application of the SFs during the analysis (which is repeated for each analysis). Part 1 of both MD and MD_LSMG is computationally more expensive compared to GAUSS and TERR_DIFF, while part 2 is nearly the same as TERR_DIFF. MD_LSMG is computationally cheaper than MD, because adding landwater contrasts limits the region of influence and hence speeds convergence. The timing for part 1 is done without limiting the observation's influence region. Thus, the computational costs are affected by the domain size.

To eliminate the domain-size effect, the SFs are calculated within an influence region (a square here) of the observation. The radius of the circle inscribed in the square was set to $300 \mathrm{~km}$, which is slightly greater than the radius of influence (ROI; $273.14 \mathrm{~km}$ ) calculated in the ADAS based on $R_{h}$ for the first pass. Now the execution time for calculating the SFs is reduced $36.5 \%$ for MD and 33\% for MD_LSMG [see item (*) in Table 5]. 


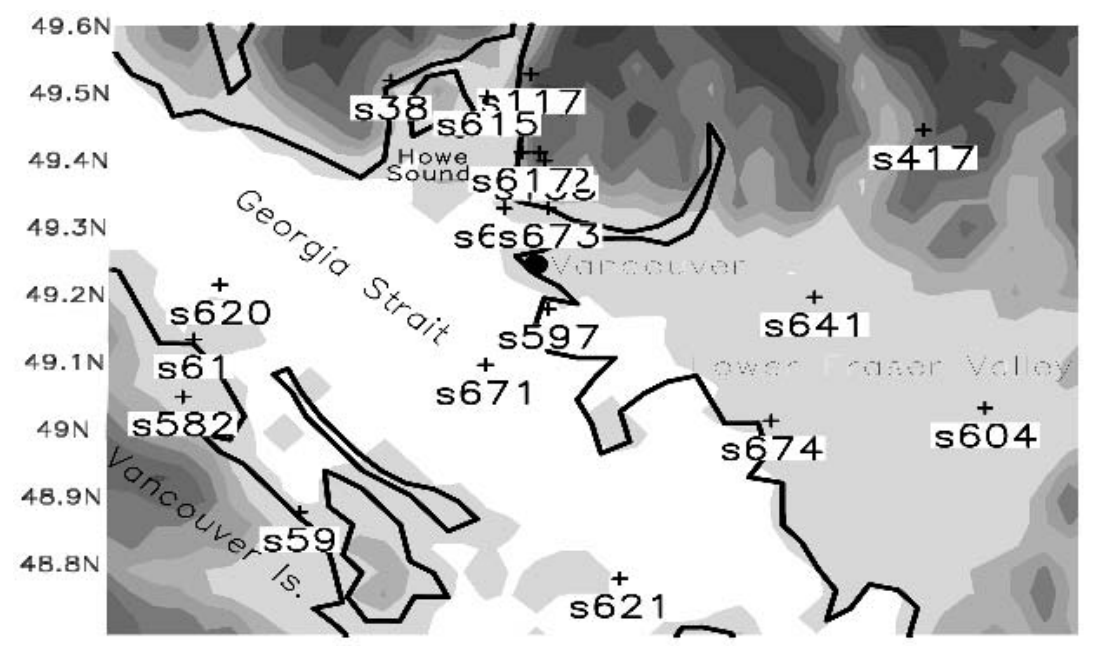

123.8W 123.6W 123.4W 123.2W 123 W 122.8 W 122.6 W 122.4 W $122.2 W$

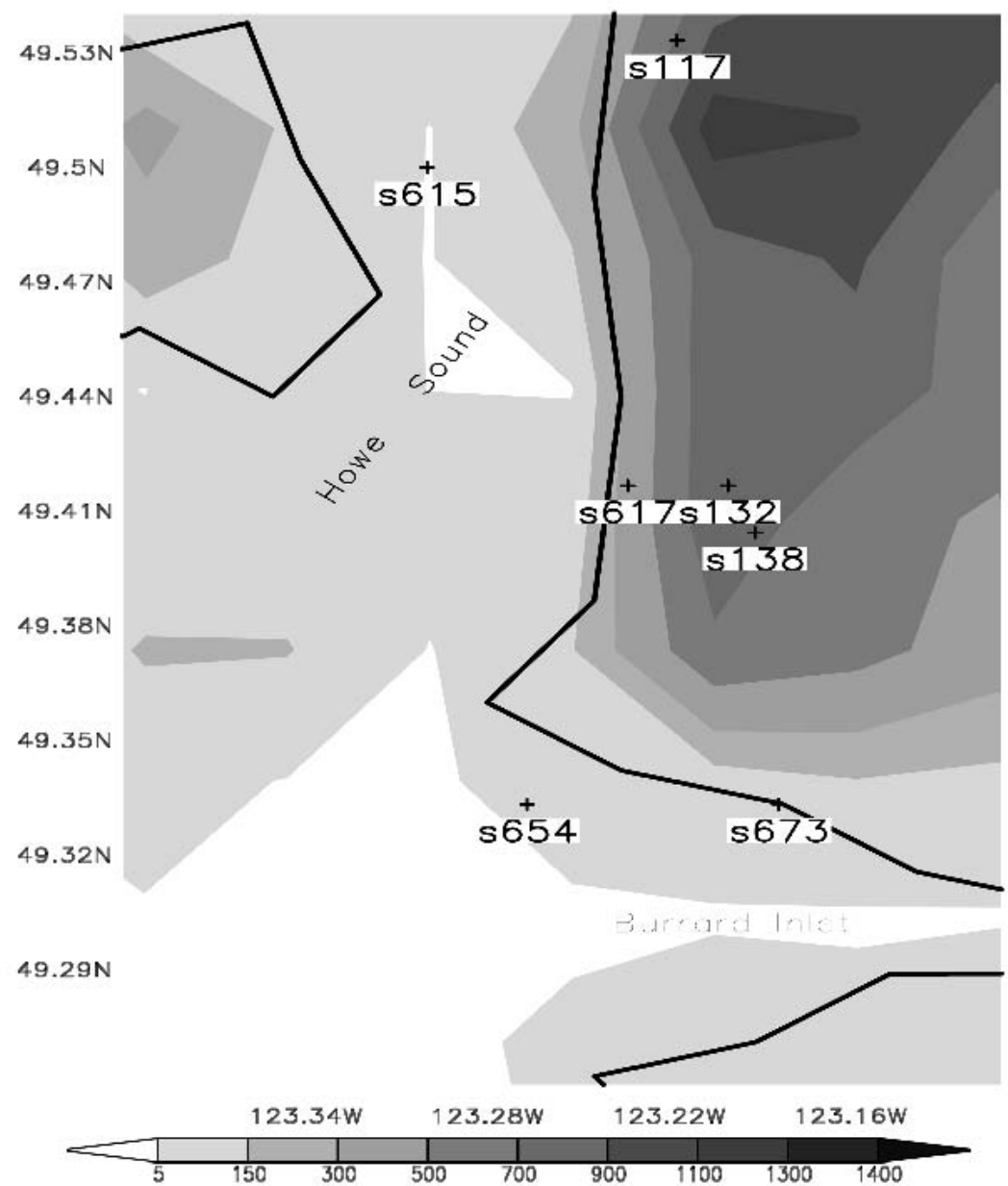

FIG. 11. The northern half of the Georgia Basin area. The surface stations are shown by pluses, below which are station IDs. Station information is in Table 2. The bottom plot is zoomed to the top center of the top plot. Terrain elevations (m), indicated by shading, are from unsmoothed terrain data resolved by the NWP model at $3-\mathrm{km}$ grid spacing. Darker shading represents higher elevations, with a maximum elevation difference of (top) $1374 \mathrm{~m}$ and (bottom) $1200 \mathrm{~m}$. 
TABLE 2. Surface stations for analysis and verification. Station IDs are from the Emergency Weather Net database. For the land-sea (LS) mask, 1 stands for land and 0 corresponds to ocean or water.

\begin{tabular}{|c|c|c|c|c|c|c|c|}
\hline Full name & Station ID & Lat $(\mathrm{N})$ & Lon $(\mathrm{W})$ & Elevation (m) & Agency & LS & Purposes \\
\hline Port Mellon & 38 & $49.5228^{\circ}$ & $123.4822^{\circ}$ & 3 & WLAP & 1 & \multirow{8}{*}{ Analysis } \\
\hline MT Strachan & 132 & $49.4167^{\circ}$ & $123.2000^{\circ}$ & 1420 & МОТН & 1 & \\
\hline Gold CK & 417 & $49.4472^{\circ}$ & $122.4750^{\circ}$ & 794 & HYDR & 1 & \\
\hline Abbotsford ARPT & 604 & $49.0333^{\circ}$ & $122.3667^{\circ}$ & 58 & $\mathrm{EC}$ & 1 & \\
\hline Saturna Island & 621 & $48.7833^{\circ}$ & $123.0500^{\circ}$ & 24 & EC & 0 & \\
\hline Pitt Meadows & 641 & $49.2000^{\circ}$ & $122.6833^{\circ}$ & 5 & EC & 1 & \\
\hline Point Atkinson CS & 654 & $49.3333^{\circ}$ & $123.2667^{\circ}$ & 35 & EC & 0 & \\
\hline Nanaimo ARPT & 582 & $49.0500^{\circ}$ & $123.8667^{\circ}$ & 28 & $\mathrm{EC}$ & 1 & \\
\hline Crofton & 59 & $48.8803^{\circ}$ & $123.6458^{\circ}$ & 20 & WLAP & 0 & \multirow{11}{*}{ Verification } \\
\hline Harmac Pacific & 61 & $49.1353^{\circ}$ & $123.8475^{\circ}$ & 23 & WLAP & 0 & \\
\hline Deeks Peak & 117 & $49.5333^{\circ}$ & $123.2167^{\circ}$ & 1280 & МOTH & 1 & \\
\hline MT Strachan Precip & 138 & $49.4044^{\circ}$ & $123.1911^{\circ}$ & 1220 & МOTH & 1 & \\
\hline Vancouver INTL ARPT & 597 & $49.1833^{\circ}$ & $123.1833^{\circ}$ & 2 & $\mathrm{EC}$ & 1 & \\
\hline Pam Rocks & 615 & $49.5000^{\circ}$ & $123.3000^{\circ}$ & 10 & $\mathrm{EC}$ & 0 & \\
\hline Discovery Islands CS & 617 & $49.4167^{\circ}$ & $123.2333^{\circ}$ & 15 & EC & 1 & \\
\hline Entrance Island & 620 & $49.2167^{\circ}$ & $123.8000^{\circ}$ & 3 & EC & 0 & \\
\hline Sand Heads CS & 671 & $49.1000^{\circ}$ & $123.3000^{\circ}$ & 15 & EC & 0 & \\
\hline West Vancouver & 673 & $49.3333^{\circ}$ & $123.1833^{\circ}$ & 178 & EC & 1 & \\
\hline White Rock & 674 & $49.0167^{\circ}$ & $122.7667^{\circ}$ & 13 & EC & 1 & \\
\hline
\end{tabular}

\section{Summary and discussion}

An MD approach and its shoreline refinement are proposed for surface-data analysis on terrain-following surfaces in mountainous/coastal terrain. The resulting SFs and CTDs are then incorporated into the ADAS.

For the cases examined here, the new scheme is compared with the original scheme (GAUSS) in the ADAS (ARPS5.0.0 Beta8), and the scheme (TERR_DIFF) developed by Miller and Benjamin (1992). It is found that the MD approach can better account for both terrain-

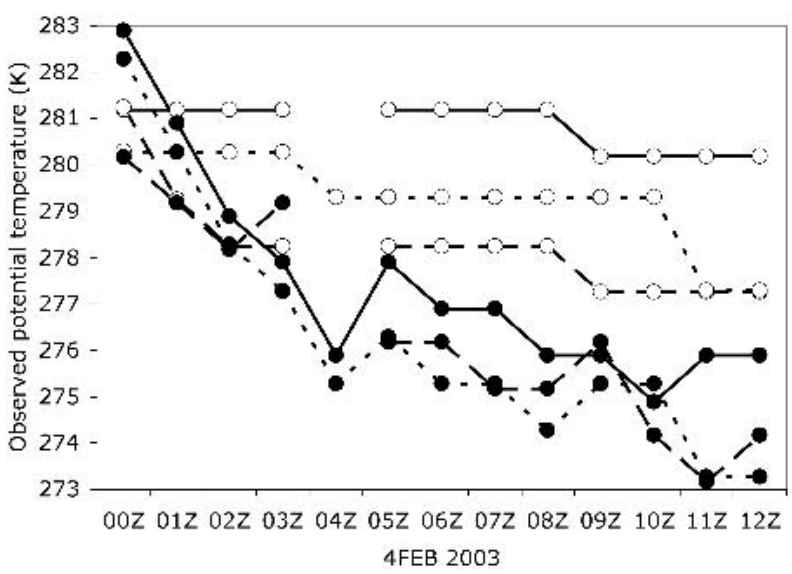

FIG. 12. Observed potential temperature (derived from observed temperature) for stations over water (lines with open circles) and over land (lines with filled circles) during 0000-1200 UTC 4 Feb 2003. Stations over water are Entrance Island (620, solid line), Pam Rocks (615, dashed line), and Sand Heads CS (671, dotted line). Stations over land are West Vancouver (673, solid line), Vancouver INTL ARPT (597, dashed line), and White Rock (674, dotted line). Breaks in the graph denote periods for which no observations were reported. 0000 UTC corresponds to 1600 PST (late afternoon), and 1200 UTC is 0400 PST (early morning). height and valley differences in the analysis of observation increments over mountainous regions. The refined MD approach can further account for land-sea contrasts and is recommended for use in mountainous, coastal terrain such as southwestern BC.

The one-time, initial computational cost of the MD approach is greater than that of either GAUSS or TERR_DIFF because of the need to calculate the SFs. However, for any fixed set of the free parameters, the resulting SFs can be saved as a fixed file and can be applied unchanged for each day's analysis.

The results from the real-observation case might be further improved if the land/sea-breeze frontal location is used to define the edges of the land mask, rather than the actual coastline. However, determining the position of a sea/land-breeze front increases the complexity and requires that the SFs be recomputed during every analysis. The real-data case shows encouraging results

TABLE 3. Number of reporting stations for analysis and verification at each analysis time on $4 \mathrm{Feb} 2003$.

\begin{tabular}{ccc}
\hline \hline & \multicolumn{2}{c}{ No. of stations } \\
\cline { 2 - 3 } Time (UTC) & Analysis & Verification \\
\hline 0000 & 8 & 11 \\
0100 & 8 & 11 \\
0200 & 8 & 11 \\
0300 & 8 & 11 \\
0400 & 4 & 7 \\
0500 & 7 & 11 \\
0600 & 6 & 11 \\
0700 & 7 & 11 \\
0800 & 7 & 11 \\
0900 & 7 & 11 \\
1000 & 7 & 11 \\
1100 & 7 & 11 \\
1200 & 7 & 11 \\
\hline
\end{tabular}



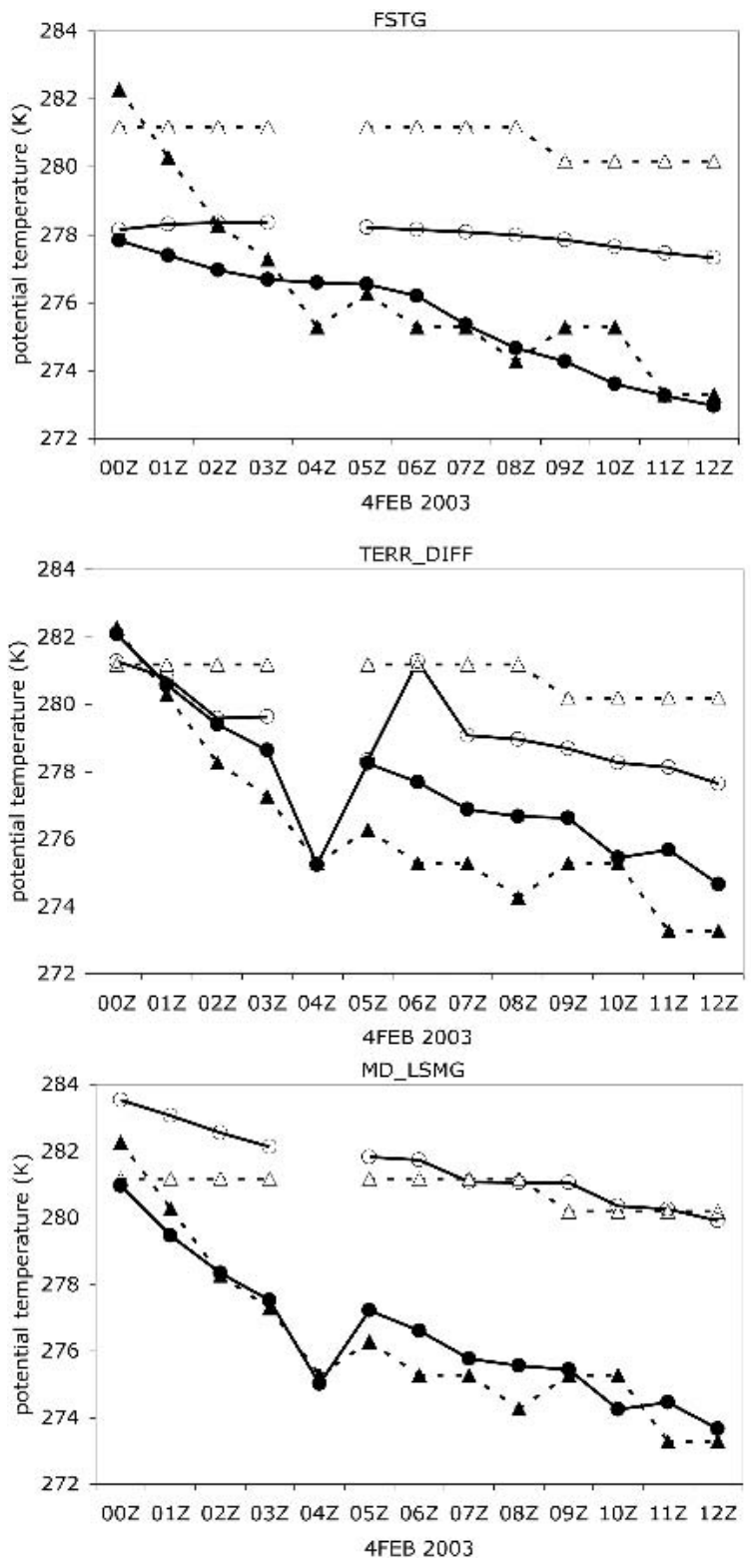

for the MD approach, even with land-water contrasts fixed at the coastlines.

To use the MD approach in mountainous/coastal terrain, fine-resolution NWP models (i.e., $\Delta x<5 \mathrm{~km}$ ) are recommended, for two reasons. First, the SF is a function of the elevations of analysis GPs; thus, there is a need to resolve all important ridges and valleys. Second, the quality of the analyses in data-sparse ridges or valleys depends strongly on the quality of the first guess from the NWP models.

The MD technique is developed under the intravalley and intervalley decorrelation assumptions. Nonetheless, one can imagine scenarios where the observation in one valley might happen to be well correlated with the air state in a neighboring valley. During a fair-
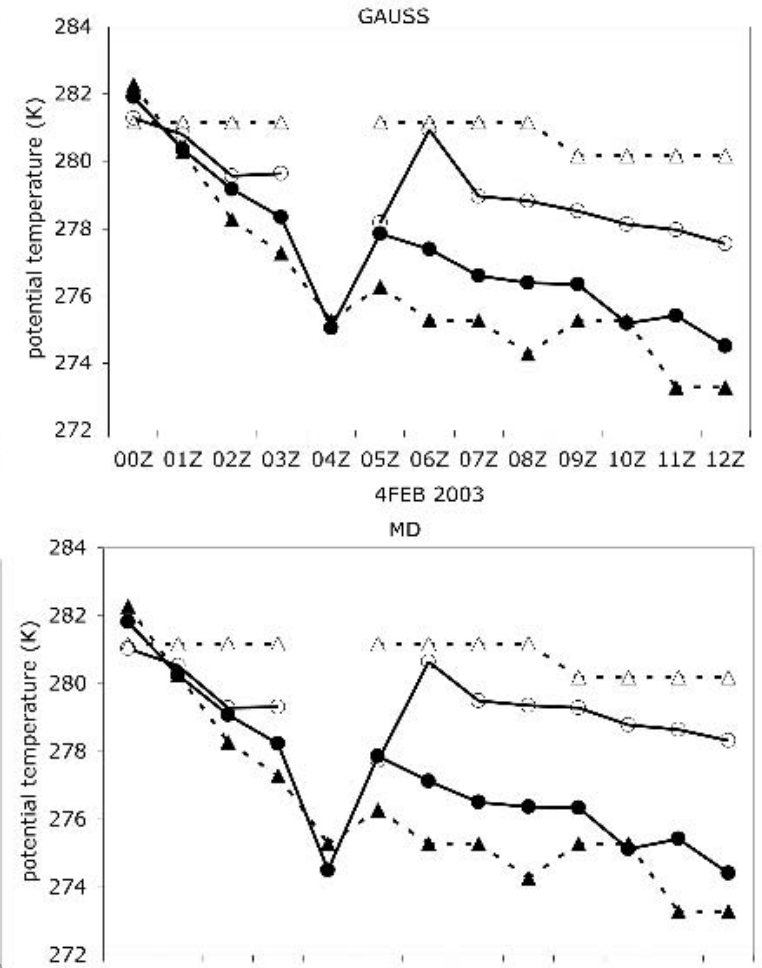

$00 Z 01 Z 02 Z 03 Z 04 Z 05 Z 06 Z \quad 07 Z 08 Z 09 Z 10 Z 11 Z 12 Z$ 4FEB 2003

FIG. 13. Time series of observed potential temperature and the [first guess (FSTG) or analyzed] potential temperature from four assimilation experiments for two stations. Observations at Entrance Island over water: dashed line with open triangles. Observations at White Rock over land: dashed line with solid triangles. Analyses at Entrance Island: solid line with open circles. Analyses at White Rock: solid line with filled circles. Analyses are better when the solid lines are closer to the respective dashed lines.

weather event with strong solar heating, the BL could be deeper than the mountain-ridge height, allowing turbulence to mix air between the two valleys. Or during strong synoptic forcing, high winds and intense turbulence could inject similar air into both valleys and/or homogenize the air in both. For these situations, running the forecast model after initialization will mix the air in neighboring valleys due to resolved advection and parameterized turbulence, even if the initialization spreads the observations only within one valley.

Sensitivity tests on the MD free parameters are performed for the real-data case (appendix). A subset of available observations are analyzed using various values of the free parameters, and the analyses are verified against the remaining observations. Nrmses are found 

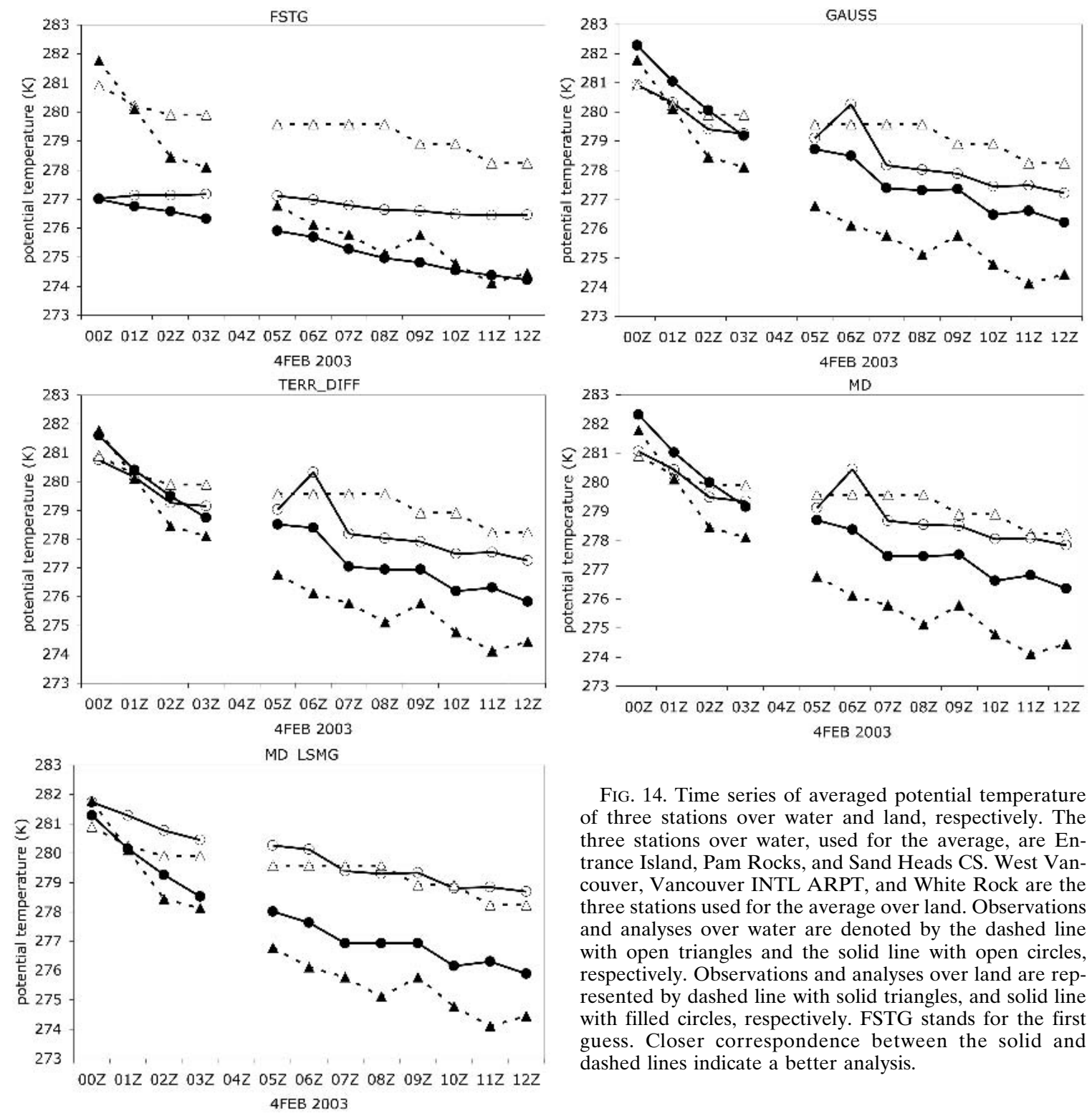

FIG. 14. Time series of averaged potential temperature of three stations over water and land, respectively. The three stations over water, used for the average, are Entrance Island, Pam Rocks, and Sand Heads CS. West Vancouver, Vancouver INTL ARPT, and White Rock are the three stations used for the average over land. Observations and analyses over water are denoted by the dashed line with open triangles and the solid line with open circles, respectively. Observations and analyses over land are represented by dashed line with solid triangles, and solid line with filled circles, respectively. FSTG stands for the first guess. Closer correspondence between the solid and dashed lines indicate a better analysis.

to be far more sensitive to zref2 than to zref1, and the nrmse sensitivity to zref2 shows a daily cycle, corresponding to the characteristics of the BL. This implies that one could automate operationally detecting decorrelated weather versus well-mixed events by using observed BL depth (if available) as zref2 during daily analyses. Further experiments will be required to investigate the sensitivities for other times and locales. The optimum values of the free parameters might be dependent on weather, season, and topography. The results shown here suggest that the free parameters can be determined via sensitivity tests over a substantial period of daily analyses.

For GAUSS and TERR_DIFF, a shorter $R_{h}$ could be used to successfully reduce the intervalley spreading

TABLE 4. Verification of analyzed potential temperatures in terms of bias, mean absolute error (mae), and normalized rootmean-square error (nrmse) for all reporting verification stations during the analysis period from 0000 to 1200 UTC 4 Feb 2003. N equals number of stations times the number of observation times. Nrmse is root-mean-square error (rmse) for each experiment normalized by the rmse of the first guess (FSTG). Percent improvement of the rmse is with respect to FSTG.

\begin{tabular}{lccccc}
\hline \hline Experiment & $\mathrm{N}$ & $\begin{array}{c}\text { Bias } \\
(\mathrm{K})\end{array}$ & $\begin{array}{c}\text { Mae } \\
(\mathrm{K})\end{array}$ & $\begin{array}{c}\text { Nrmse } \\
(\mathrm{K})\end{array}$ & $\begin{array}{c}\text { Percent } \\
\text { improvement }\end{array}$ \\
\hline FSTG & 139 & -2.6832 & 2.7624 & 1.0 & 0 \\
GAUSS & 139 & -0.5625 & 1.7565 & 0.6610 & 34 \\
TERR_DIFF & 139 & -0.6401 & 1.6482 & 0.6317 & 37 \\
MD & 139 & 0.2344 & 1.3069 & 0.4943 & 51 \\
MD_LSMG & 139 & -0.0051 & 1.1956 & 0.4433 & 56
\end{tabular}


TABLE 5. Execution time (s) for each analysis experiment on one processor of a High-Performance Computing Linux SuperCluster, with 1-GHz Pentium III CPU. The results are obtained from a surface-only analysis at 0100 UTC 4 Feb 2003, when all 169 observations are used for analysis within a domain of $257 \times 205$ grid points, with $3-\mathrm{km}$ grid spacing. The parameters used in the mother-daughter approach are $a=2, b=2$, zref1 $=750 \mathrm{~m}$ and zref $2=750 \mathrm{~m}$. For the two MD approaches, item 1 is the one-time setup cost without limiting search radius, item 2 is the execution time for its application to this test domain, and item * is also the one-time setup cost but with limiting search radius to $300 \mathrm{~km}$.

\begin{tabular}{lc}
\hline \hline Experiment & Execution time (s) \\
\hline GAUSS & 22.99 \\
TERR_DIFF & 28.12 \\
MD (1) & 3902.03 \\
$(2)$ & 29.96 \\
$(*)$ & 2476.80 \\
MD_LSMG (1) & 2833.89 \\
& 29.93 \\
$(2)$ & 1897.60 \\
\hline
\end{tabular}

from a disconnected neighboring valley (appendix). However, this strategy also reduces the potentially good intravalley spreading. In addition, a universal $R_{h}$ might be hard to find in highly variable terrain. The MD approach suppresses intervalley spreading while allowing intravalley spreading over a longer distance. This approach automatically accounts for the elevations of surface stations and analysis GPs.

The ultimate goal is to provide better input fields for fine-resolution NWP models. To produce improved analyses to drive the $\mathrm{MC} 2$, we plan to combine the mesoscale surface analyses from the MD approach with the coarse-resolution Eta analyses from NCEP, and to compare verification statistics with MC2 control runs driven by unmodified Eta initial conditions. We further plan to modify MD to spread free-atmosphere mountain-top observations differently than BL valley observations.

Acknowledgments. We thank Joshua Hacker from NCAR for his suggestions, and Stephane Chamberland of RPN for MC2 user support. We also thank Henryk Modzelewski, George Hicks, Yongmei Zhou, John Spagnol, and other colleagues at UBC. Thanks also to three reviewers, including Steven Lazarus, John Horel and Keith Brewster. Grant support came from the Canadian Natural Science and Engineering Research Council, the BC Forest Investment Account, Environment Canada (EC), and the Canadian Foundation for Climate and Atmospheric Science. Observation data from the Emergency Weather Net were provided by EC, BC Ministry of Transportation and Highways, BC Ministry of Water Land and Air Protection, and BC Hydro. Geophysical Disaster CFD Center computers were used, funded by the Canadian Foundation for Innovation, the BC Knowledge Development Fund, and UBC.

\section{APPENDIX}

\section{Sensitivity Tests}

This appendix provides a sensitivity analysis of MD_LSMG to different values of the free parameters for the case from section $6 \mathrm{~b}$. The analysis and verification observations remain the same. This single case is insufficient to determine the optimum values. However, it does indicate some sensitivity characteristics.

First, we vary zref1 and zref2 from 250 to $3000 \mathrm{~m}$ every $250 \mathrm{~m}$, while holding $a=2$ and $b=2$. Recall that zref1 and zref2 are the maximum effective BL heights through which surface observations are felt.

Figure A1 shows nrmses versus zref1 and zref2 for

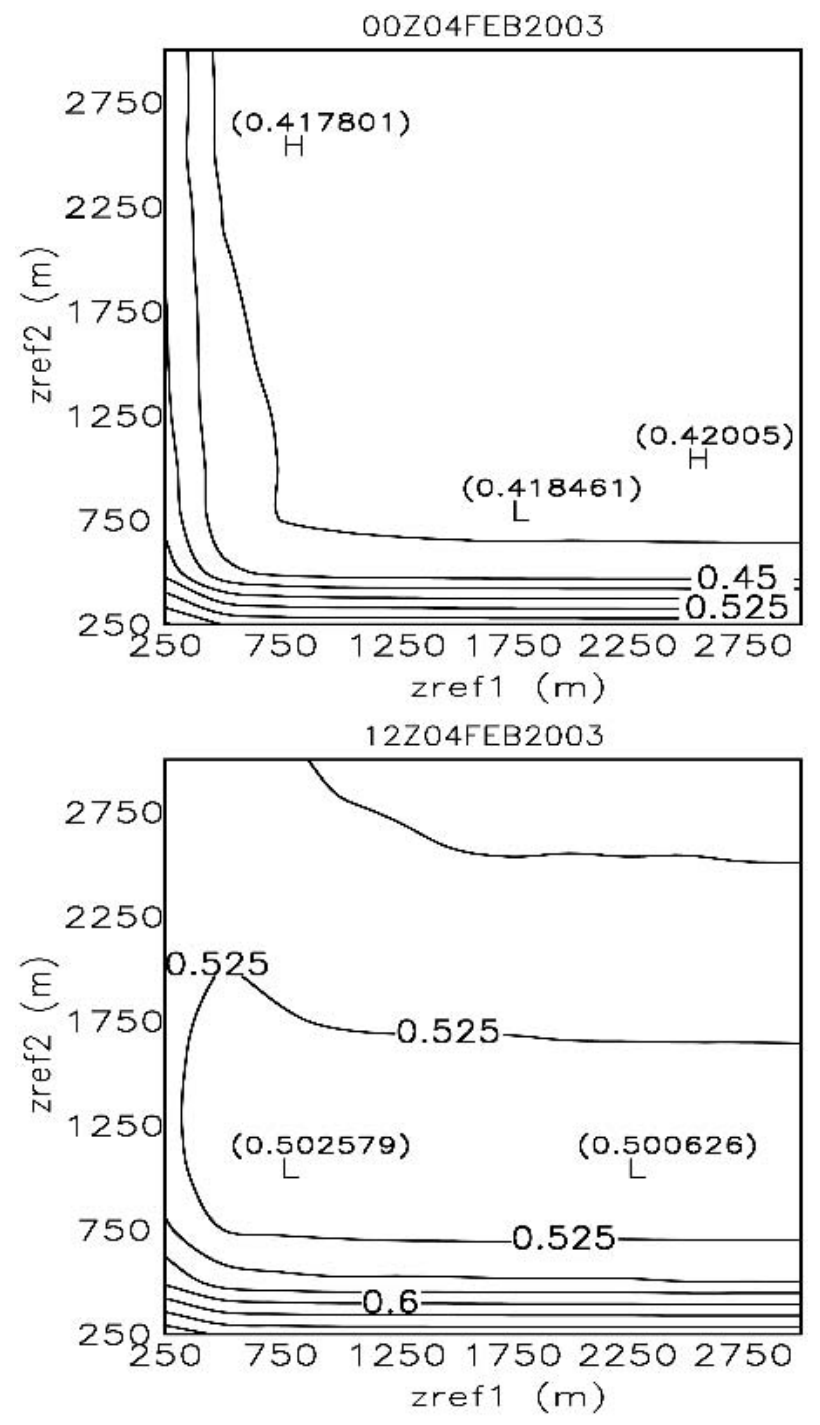

FIG. A1. Nrmse of analyses vs zref1 and zref2 when $a=2$ and $b=2$. Contour interval is $0.025 \mathrm{~K}$. (top) Late afternoon (0000 UTC 4 Feb 2003); (bottom) early morning (1200 UTC 4 Feb 2003). Smaller nrmse is better. 
0000 UTC (1600 PST) and 1200 UTC (0400 PST) 4 February 2003. At both 0000 and 1200 UTC, nrmses are less than 1.0 for any values of zref1 and zref 2 within the range $250-3000 \mathrm{~m}$. Thus, the analyses agree with the observations better than the first guess. Nrmse is not sensitive to zref1 when zref1 $>750 \mathrm{~m}$, or zref $2<500 \mathrm{~m}$. This is because the elevation differences between a mother GP and its immediate daughter GPs are usually small. Nrmse is far more sensitive to zref2 than to zref1, as zref2 defines the maximum effective height above the observation, and because the elevation differences between the observation and the analysis GPs vary considerably.

Figure A1 shows different features at 0000 and 1200 UTC. In late afternoon (0000 UTC), nrmse shows small sensitivity to zref $1>750 \mathrm{~m}$ and zref $2>750 \mathrm{~m}$. In early morning (1200 UTC), lower nrmse is confined to a narrow band from zref1 $=500$ to $3000 \mathrm{~m}$ and from zref2 $=$ 1000 to $1250 \mathrm{~m}$. Similar sensitivity tests from 0100 to 1100 UTC indicate a transition at 0200 UTC (not shown). The behaviors correspond to the characteristics of the evolving BL.

Second, we vary $a$ and $b$ from 0.5 to 4.0 every 0.5 for 1200 UTC 4 February 2003. For these experiments, zref1 $=2250 \mathrm{~m}$ and zref $2=1000 \mathrm{~m}$, which were the best values from the previous tests. As shown in Fig. A2, $a$ $=2$ and $b=2$ (or $a=1$ and $b=2.5$ ) yield lower nrmses.

Using the CTD in the MD approach effectively limits the region of influence in complex terrain (section 5). GAUSS and TERR_DIFF ROI sensitivity tests are performed by varying horizontal correlation length scale $R_{h}$ (used to calculate ROI in the ADAS) from 100 to $10 \mathrm{~km}$ every $10 \mathrm{~km}$ for the first and second Bratseth

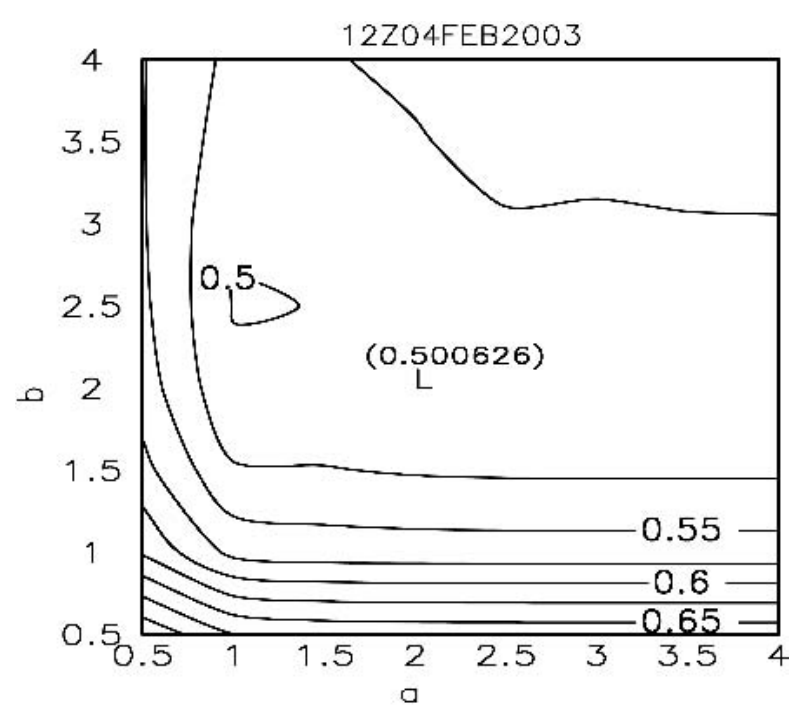

FIG. A2. Nrmse of analyses (1200 UTC 4 Feb 2003) vs $a$ and $b$ when zref1 $=2250 \mathrm{~m}$ and zref $2=1000 \mathrm{~m}$, which were the best values for 1200 UTC from Fig. A1. Contour interval is $0.025 \mathrm{~K}$. Smaller nrmse is better. passes. For each test, the third Bratseth pass reduces $R_{h}$ by $70 \%$, while the fourth and fifth passes reduce $R_{h}$ by $70 \%$ from the third pass.

For the virtual-observation case (section 6a), rmse decreases rapidly with decreasing $R_{h}$ for both GAUSS and TERR_DIFF (Fig. A3), as the correction from o1 becomes negligible in the Lillooet River Valley. When $R_{h}=20 \mathrm{~km}$, a minimal rmse is found to be $0.3385 \mathrm{~K}$ for GAUSS and $0.4105 \mathrm{~K}$ for TERR_DIFF. The rmse with $R_{h}=20 \mathrm{~km}$ is reduced about $37 \%$ for GAUSS and $24 \%$ for TERR_DIFF from the first guess. While such small values of $R_{h}$ successfully reduce intervalley spreading, they do so at the expense of reducing the potentially good intravalley spreading. The MD approach avoids this problem.
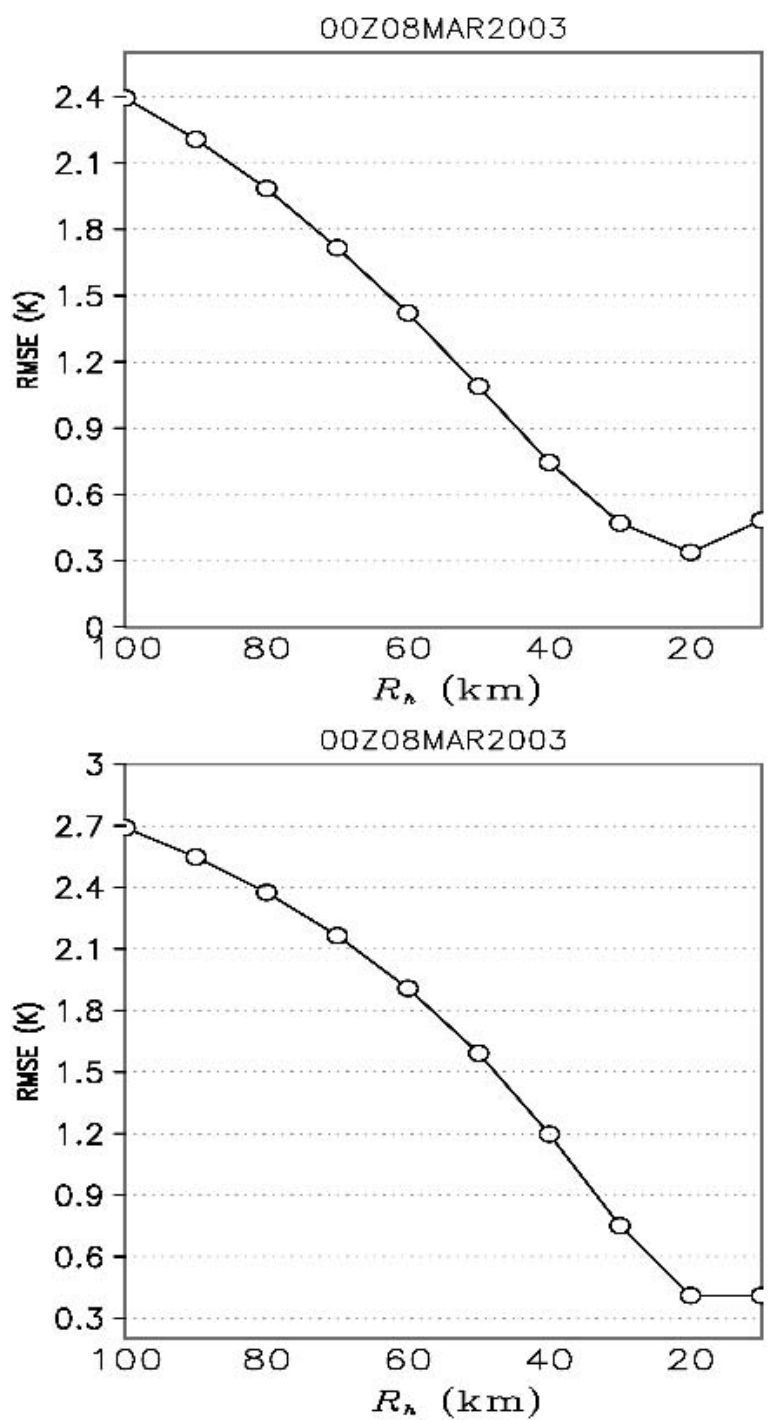

FIG. A3. Rmse of analyses (0000 UTC 8 Mar 2003) vs $R_{h}$ used in the first and second Bratseth passes. The third Bratseth pass has an $R_{h}$ that is reduced by $70 \%$ from the second pass, while the fourth and fifth Bratseth passes have a $R_{h}$ that is reduced by $70 \%$ from the third pass. (top) GAUSS; (bottom) TERR_DIFF. 
Similar tests are performed for the real-observation case (section 6b). Figure A4 shows nrmses versus $R_{h}$ used in the first and second Bratseth passes for 1200 UTC 4 February 2003. For both GAUSS and TERR_DIFF, nrmses are less than 1.0. Nrmse shows small sensitivity to $R_{h}$ when $R_{h}>40 \mathrm{~km}$ but relatively large sensitivity when $R_{h}<40 \mathrm{~km}$. A minimal nrmse is found at $R_{h}=20 \mathrm{~km}$ for GAUSS and at $R_{h}=10 \mathrm{~km}$ for TERR_DIFF. Identical tests are performed for 0000 UTC (Fig. A5). Different from the 1200 UTC results, $R_{h}=100$ or $90 \mathrm{~km}$ produces lower nrmses for both GAUSS and TERR_DIFF.

The ROI sensitivity for the real-observation case is much smaller than that for the virtual-observation case.
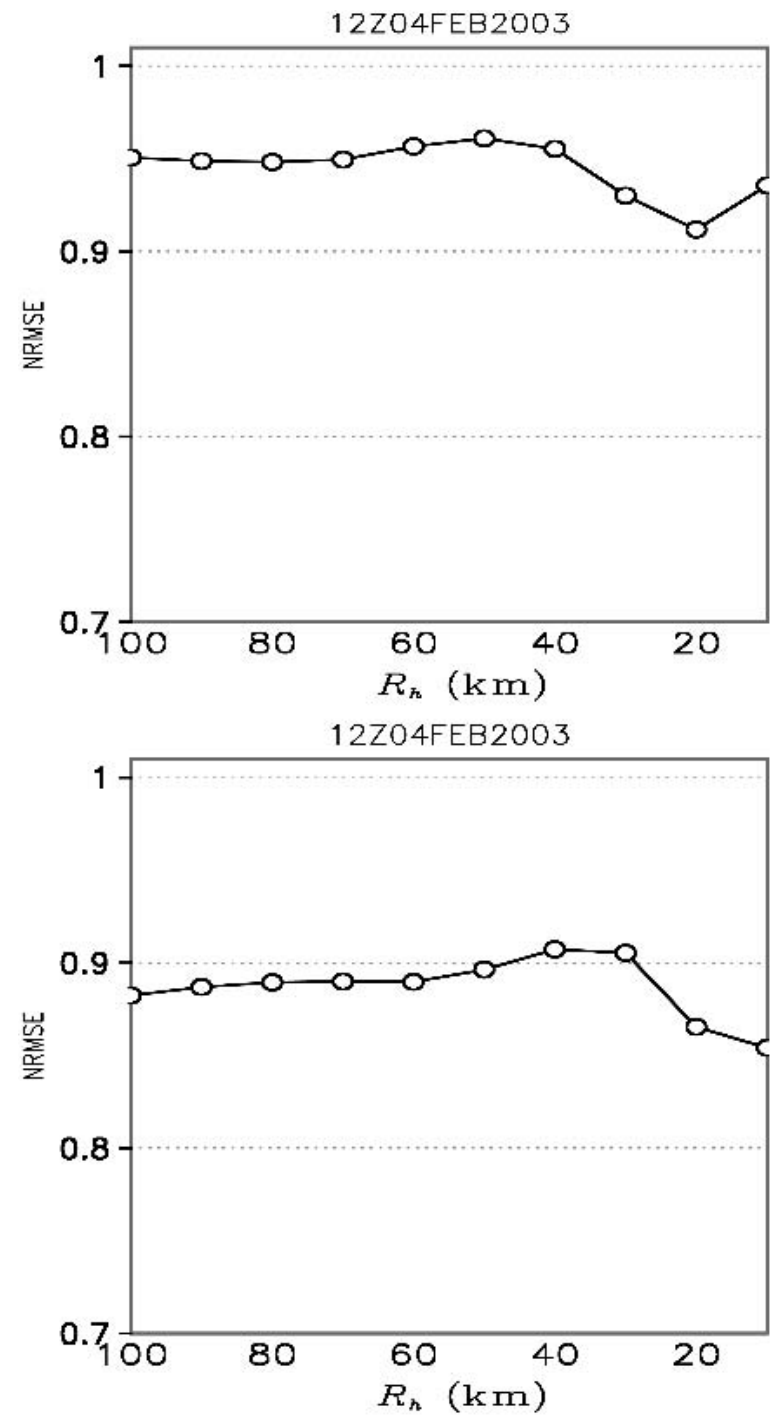

FIG. A4. Nrmse of analyses (1200 UTC 4 Feb 2003) vs $R_{h}$ used in the first and second Bratseth passes. The third Bratseth pass has an $R_{h}$ that is reduced by $70 \%$ from the second pass, while the fourth and fifth Bratseth passes have a $R_{h}$ that is reduced by $70 \%$ from the third pass. (top) GAUSS; (bottom) TERR_DIFF. Smaller nrmse is better.
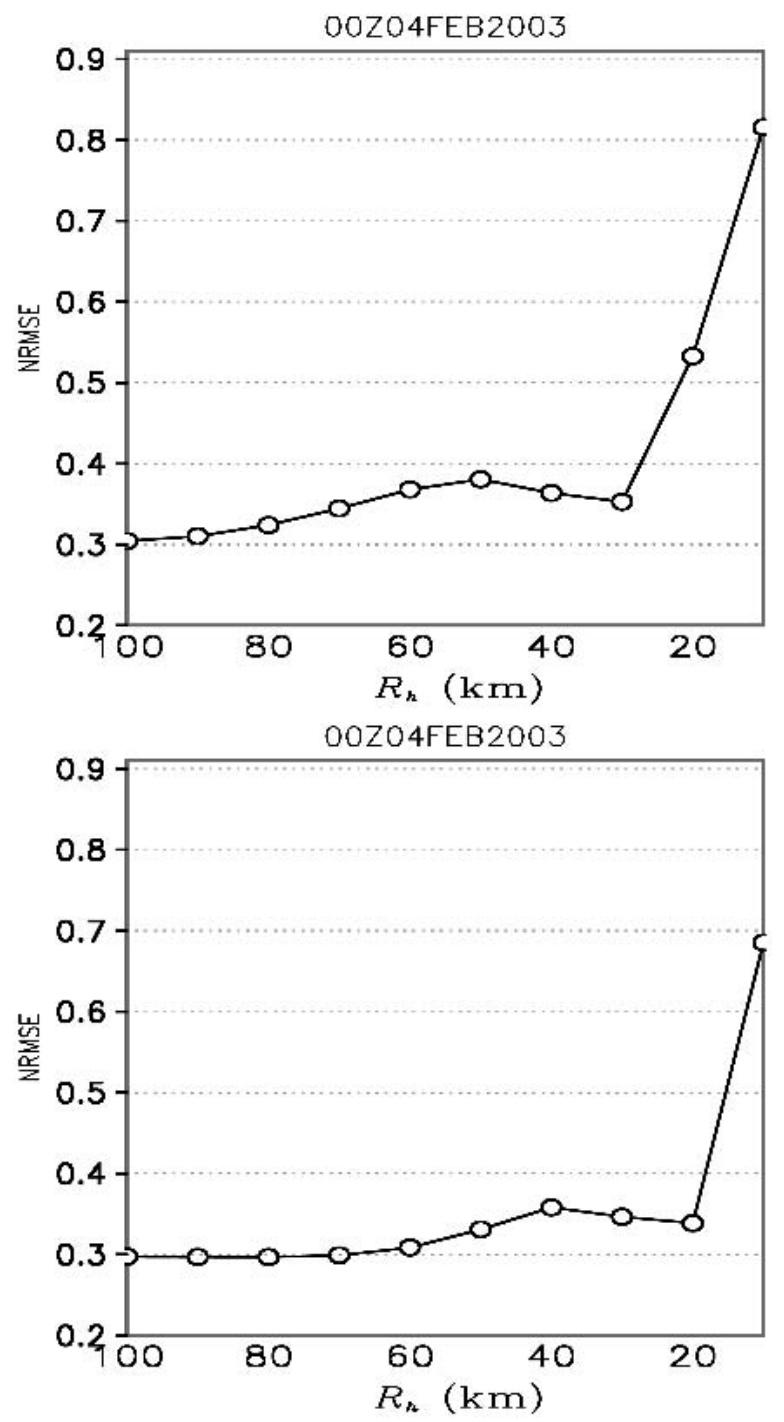

FIG. A5. Same as Fig. A4, but for 0000 UTC 4 Feb 2003. (top) GAUSS; (bottom) TERR_DIFF. Smaller nrmse is better.

This is not surprising, considering that only two observations in the two adjacent valleys were used for the virtual-observation case. These results indicate that a prescribed $R_{h}$ does not work everywhere in highly variable terrain. An $R_{h}$ that depends on the elevations of surface stations and analysis GPs might help to improve the analyses from GAUSS and TERR_DIFF. In complex terrain, an effective $R_{h}$ might not only depend on the average station separation, but also on the geographic regions, seasons, and weather.

\section{REFERENCES}

Arnold, C. P., and C. H. Dey, 1986: Observing systems simulation experiments: Past, present, and future. Bull. Amer. Meteor. Soc., 67, 687-695.

Barnes, S. L., 1964: A technique for maximizing details in numerical weather map analysis. J. Appl. Meteor., 3, 396-409. 
Benjamin, S. G., K. Brewster, R. Brummer, B. Jewett, T. W Schlatter, T. L. Smith, and P. A. Stamus, 1991: An isentropic three-hourly data assimilation system using ACARS aircraft observations. Mon. Wea. Rev., 119, 888-906.

Benoit, R., M. Desgagne, P. Pellerin, S. Pellerin, Y. Chartier, and S. Desjardins, 1997: The Canadian MC2: A semi-Lagrangian, semi-implicit wide band atmospheric model suited for finescale process studies and simulation. Mon. Wea. Rev., 125, 2382-2415.

Bouttier, F., 1993: The dynamics of error covariances in a barotropic model. Tellus, 45A, 408-423.

Bratseth, A. M., 1986: Statistical interpolation by means of successive corrections. Tellus, 38A, 439-447.

Brewster, K., 1996: Application of a Bratseth analysis scheme including Doppler radar data. Preprints, 15th Conf. on Weather Analysis and Forecasting, Norfolk, VA, Amer. Meteor. Soc., 92-95.

CAPS, 1995: ARPS version 4.0 user's guide, Supplement 1: 3-D analysis with ARPS data assimilation system: ADAS version 2.3. Center for Analysis and Prediction of Storms, University of Oklahoma. [Available online at http://www.caps.ou.edu/ ARPS/ADAS.doc.html.]

Case, J. L., J. Manobianco, T. D. Oram, T. Garner, P. F. Blottman, and S. M. Spratt, 2002: Local data integration over eastcentral Florida using the ARPS Data Analysis System. Wea. Forecasting, 17, 3-26.

Ciliberti, C. M., J. D. Horel, and S. M. Lazarus, 2000: Sensitivity experiments with a high resolution data assimilation scheme. Preprints, Ninth Conf. on Mountain Meteorology, Aspen, CO, Amer. Meteor. Soc., 413-416.

_ - J. D. Horel, and S. M. Lazarus, 1999: An analysis of a cold frontal passage over complex terrain in northwest Utah. Preprints, Eighth Conf. on Mesoscale Processes, Boulder, CO, Amer. Meteor. Soc., 459-462.

Daley, R., 1991: Atmospheric Data Analysis. Cambridge University Press, $457 \mathrm{pp}$

Desroziers, G., 1997: A coordinate change for data assimilation in spherical geometry of frontal structures. Mon. Wea. Rev., 125, 3030-3038.

De Wekker, S. F. J., M. Kossmann, and F. Fiedler, 1997: Observations of daytime mixed layer depths over mountainous terrain during the TRACT field campaign. Preprints, 12th Symp. on Boundary Layers and Turbulence, Vancouver, BC, Canada, Amer. Meteor. Soc., 498-499.

Gauthier, P., P. Courtier, and P. Moll, 1993: Assimilation of simulated wind lidar data with a Kalman filter. Mon. Wea. Rev., 121, 1803-1820.

Hessler, G., 1984: Experiments with statistical objective analysis techniques for representing a coastal surface temperature field. Bound.-Layer Meteor., 28, 375-389.

Horel, J., T. Potter, L. Dunn, W. J. Steenburgh, M. Eubank, M. Splitt, and D. J. Onton, 2002: Weather support for the 2002 Winter Olympic and Paralympic Games. Bull. Amer. Meteor. Soc., 83, 227-240.

Houtekamer, P. L., and H. L. Mitchell, 2001: A sequential ensemble Kalman filter for atmospheric data assimilation. Mon. Wea. Rev., 129, 123-137.
— man filter technique. Mon. Wea. Rev., 126, 796-811.

Kalthoff, N., H.-J. Binder, M. Kossmann, R. Vogtlin, U. Corsmeier, F. Fiedler, and H. Schlager, 1998: Temporal evolution and spatial variation of the boundary layer over complex terrain. Atmos. Environ., 32, 1179-1194.

Kossmann, M., R. Vogtlin, U. Corsmeier, B. Vogel, F. Fiedler, H.-J. Binder, N. Kalthoff, and F. Beyrich, 1998: Aspects of the convective boundary layer structure over complex terrain. Atmos. Environ., 32, 1323-1348.

Krishnamurti, T. N., and L. Bounoua, 1996: An Introduction to Numerical Weather Prediction Techniques. CRC Press, 293 pp.

Lanzinger, A., and R. Steinacker, 1990: A fine mesh analysis scheme designed for mountainous terrain. Meteor. Atmos. Phys., 43, 213-219.

Laprise, R., D. Caya, G. Bergeron, and M. Giguère, 1997: The formulation of the André Robert MC2 (mesoscale compressible community) model. Numerical Methods in Atmospheric and Oceanic Modelling, The André J. Robert Memorial Volume, Atmosphere-Ocean, 195-220.

Laroche, S., P. Gauthier, J. St-James, and J. Morneau, 1999: Implementation of a 3D variational data assimilation system at the Canadian Meteorological Center. Part II: The regional analysis. Atmos.-Ocean, 37, 281-307.

Lazarus, S. M., C. M. Ciliberti, J. D. Horel, and K. Brewster, 2002: Near-real-time applications of a mesoscale analysis system to complex terrain. Wea. Forecasting, 17, 971-1000.

Lenschow, D. H., B. B. Stankov, and L. Mahrt, 1979: The rapid morning boundary-layer transition. J. Atmos. Sci., 36, 21082124.

Miller, P. A., and S. G. Benjamin, 1992: A system for the hourly assimilation of surface observations in mountainous and flat terrain. Mon. Wea. Rev., 120, 2342-2359.

Stull, R. B., 1988: An Introduction to Boundary Layer Meteorology. Kluwer Academic, $666 \mathrm{pp}$.

1992: A theory for mixed-layer-top levelness over irregular topography. Preprints, 10th Symp. on Turbulence and Diffusion, Portland, OR, Amer. Meteor. Soc., 92-94.

— 1998: Studies of mountain climates, and a theory for mixedlayer-top levelness over complex topography. Geophysical Disaster Computational Fluid Dynamics Center Tech. Rep. WFRT-98-001, University of British Columbia, Vancouver, Canada.

2000: Meteorology for Scientists and Engineers. 2d ed. Brooks/Cole, 502 pp.

Thépaut, J.-N., P. Courtier, G. Belaud, and G. Lemaitre, 1996: Dynamical structure functions in a four-dimensional variational assimilation: A case study. Quart. J. Roy. Meteor. Soc., 122, 535-561.

Xue, M., K. K. Droegemeier, and V. Wong, 2000: The advanced regional prediction system (ARPS) - A multi-scale nonhydrostatic atmospheric simulation and prediction model. Part I: Model dynamics and verification. Meteor. Atmos. Phys., 75, 161-193. 